\title{
Pyrimidine metabolic rate limiting enzymes in poorly- differentiated hepatocellular carcinoma are signature genes of cancer stemness and associated with poor prognosis
}

\author{
Hsi-Wen Yeh ${ }^{1,2}$, Szu-Shuo Lee ${ }^{2,3}$, Chieh-Yu Chang ${ }^{2,4}$, Chun-Mei Hu${ }^{5}$ and Yuh-Shan \\ Jou $1,2,3,4$ \\ ${ }^{1}$ Graduate Institute of Life Sciences, National Defense Medical Center, Taipei, Taiwan \\ ${ }^{2}$ Institute of Biomedical Sciences, Academia Sinica, Taipei, Taiwan \\ ${ }^{3}$ Program in Molecular Medicine, National Yang-Ming University and Academia Sinica, Taipei, Taiwan \\ ${ }^{4}$ Taiwan International Graduate Program in Molecular Medicine, National Yang-Ming University and Academia Sinica, Taipei, \\ Taiwan \\ ${ }^{5}$ Genomic Research Center, Academia Sinica, Taipei, Taiwan \\ Correspondence to: Yuh-Shan Jou, email: jou@ibms.sinica.edu.tw \\ Keywords: hepatocellular carcinoma, poor differentiation, pyrimidine metabolism, rate-limiting enzymes, stemness \\ Received: May 04, $2017 \quad$ Accepted: July 29, $2017 \quad$ Published: September 08, 2017 \\ Copyright: Yeh et al. This is an open-access article distributed under the terms of the Creative Commons Attribution License 3.0 \\ (CC BY 3.0), which permits unrestricted use, distribution, and reproduction in any medium, provided the original author and source \\ are credited.
}

\section{ABSTRACT}

Cellular metabolism of cancer cell is generally recognized to provide energy for facilitating tumor growth, but little is known about the aberrant metabolism in tumor progression and its prognostic value. Here, we applied integrated genomic approach to uncover the aberrant expression of metabolic enzymes in poorly-differentiated human hepatocellular carcinoma (HCC) for revealing targets against HCC malignancy. A total of 135 upregulated ( 22 are rate-limiting enzymes (RLEs)) and 362 down-regulated (77 are RLEs) metabolic genes were identified and associated with poor patient survival in large-cohorts of HCC patients in TCGA-LIHC and two other independent transcriptomic studies. Ten out of 22 upregulated RLEs in poorly-differentiated HCC are critical enzymes in pyrimidine metabolism pathways in association with stemness features by gene enrichment analysis and upregulated in ALDH1 ${ }^{+}$stem-like HCC subpopulations. By focusing on three RLEs including TK1, TYMS and DTYMK of dTTP biosynthesis pathway, expression of 3 RLEs in well-differentiated HCC cells increased ALDH1 $^{+}$and spheroid stemness population but reversed by knockdown in poorlydifferentiated HCC cells. Up-regulated 3 RLEs in HCC were associated with poor patient survival in multiple cohorts. Together, we identified aberrant pyrimidine pathway in poorly-differentiated HCC promotes cancer stemness served as potential theranostic target for battling HCC tumor progression.

\section{INTRODUCTION}

Hepatocellular carcinoma (HCC), the major malignancy of liver, is the sixth most common cancer in the world and the second leading cause of cancer deaths for the last decade with around 0.8 million each of new cases and deaths annually [1]. Most successful HCC therapeutic options are surgical resection, transplantation and ablation therapy for only about $30 \%$ eligible early-stage patients, but limited efficacy to most of patients due to late-stage HCC at the time of diagnosis. The prognosis is very poor for untreated $\mathrm{HCC}$ patients with an average survival between 6 and 20 months $[2,3]$ and $40 \sim 80 \%$ of treated patients developed recurrence and metastasis within 5 years of therapy $[4,5]$. Sorafenib, a multiple kinase inhibitor, is the only FDA-approved systemic treatment to advanced-stage HCC patients with a statistically significant increase of overall survival benefit by about 3 months $[6,7]$. 
Reprogramming of cancer cell metabolism to fuel uncontrollable privilege of cell proliferation in compared with surrounding normal cells is emerging as the new hallmark of cancer [8]. Altered energy metabolism in cancer cell was first observed since 1930 by Otto Warburg that cancer cells are favored to increase glucose uptake and utilize less efficient ATP producing aerobic glycolysis in compared to the high ATP producing glucose oxidative phosphorylation in mitochondria in the normal cells [9]. Depending on the intrinsic genetic background of cancer cells and extrinsic nutrient availability and cellular interactions in the tumor microenvironment, altered cellular metabolism could support anabolic growth of cancer cells in the nutrient-rich environment, catabolic supports of cancer cell survival under limited nutrient, and fortification of redox imbalance to facilitate oncogene activation, tumor suppressor loss, and other tumorigenic stresses [10, 11]. Recent cancer genomic data revealed that different somatic mutations of metabolic genes in different cancer types such as loss of function of mutated succinate dehydrogenase (SDH) or fumarate hydratase $(\mathrm{FH})$ in certain renal cell carcinomas and mutated isocitrate dehydrogenase (IDH) 1 or 2 in glioma, acute myeloid leukemias, chondrosarcomas, and amplification of phosphoglycerate dehydrogenase (PHGDH) in estrogen receptor (ER)-negative breast cancer and melanoma further suggest that somatic alterations in metabolism could satisfy cancer-specific demands for fueling tumor growth [12-16]. Although it is generally recognized that altered cellular metabolism of cancer cells could facilitate cell proliferation and transformation, little is known about the metabolic changes that promote cancer cell aggressiveness [17-20].

Cancer cell aggressiveness is tightly associated with features of epithelial to mesenchymal transition (EMT), stemness, poor differentiation and high mobility of cancer cells leading to outcomes of drug resistance, recurrence and metastasis resulted in poor survival of cancer patients [21, 22]. To reveal how metabolic reprogramming contributes to aggressiveness and serves as theranostic target during tumor progression, we examined the altered expression of metabolic enzymes in association with histopathological feature of poor differentiation of HCC using the large number of HCC patients from TCGA cohorts. Interestingly, we identified a unique pyrimidine metabolic rate limiting enzymes (RLEs) gene signature that is altered in poorlydifferentiated HCC and correlated to the stemness of embryonic signatures and poor patient survival. With validations of experiments and $\mathrm{HCC}$ patients in multiple cohorts, we provided lines of evidence that TK1, TYMS and DTYMK the catalytic RLEs in pyrimidine biosynthesis play critical roles in cancer stemness and serve as potential therapeutic targets in poorlydifferentiated HCC.

\section{RESULTS}

\section{A unique metabolic gene expression signature in poorly-differentiated hepatocellular carcinoma patients}

To determine the involvement of metabolic genes during tumor progression of $\mathrm{HCC}$ especially focusing on tumor differentiation, we downloaded RNA transcriptomic datasets performed by next generation sequencing (RNAseq) in The Cancer Genome Atlas (TCGA) project (TCGA-LIHC) containing 50 normal liver tissues and 357 HCC samples including 227 well-differentiated HCC (Grade I and II of histological grading) and 130 poorlydifferentiated HCC (Grade III and IV) and examined the expression status of 1,706 reported metabolic genes [23]. Aided by hierarchical clustering, we found the aberrant expression of 362 downregulated and 135 upregulated enzymes are enriched in poorly-differentiated HCC in compare to that of well-differentiated HCC and normal liver samples (Figure 1A, 1B and 1E). We further validated these aberrant metabolic enzymes expression in two independent HCC datasets conducted in microarray platforms including GSE50579 (61 HCC and 7 normal samples) [24] and GSE36411 (40 HCC and 40 normal samples) [25] (Figure 1C, 1D, 1F and 1G).

\section{Functional prediction and prognostic value of aberrant expressed metabolic enzymes in poorly- differentiated HCC}

To determine the main functions of these aberrantly expressed metabolic genes, we performed pathway analysis matched to the metabolic pathways in KEGG (Kyoto Encyclopedia of Genes and Genomes) database. We found that the upregulated 135 metabolic genes particularly enriched in pyrimidine metabolism and purine metabolism whereas 362 downregulated metabolic genes were enriched in valine, leucine and isoleucine degradation and fatty acid metabolism (Figure 2A and Supplementary Figure 1A). To determine the critical enzymes participated in these metabolic pathways, we further examined the driving rate-limiting enzymes (RLEs) [26] including 22 upregulated RLEs and 77 downregulated RLEs participated in these altered metabolic pathways (Table 1). Consistently, we found that 22 upregulated RLEs (45.4\%) were mainly enriched in pyrimidine metabolism and 77 downregulated RLEs (22\%) were enriched in fatty acid metabolism (Figure 2B and Supplementary Figure 1B).

To determine the biological functions of these aberrant metabolic enzymes in poorly-differentiated HCC, we reclassified HCC patients based on the features of histological differentiation and the expression status of 22 upregulated RLEs and 77 downregulated RLEs for gene set enrichment analysis (GSEA) and matched with the annotated functional gene sets collected in the molecular signatures database. 


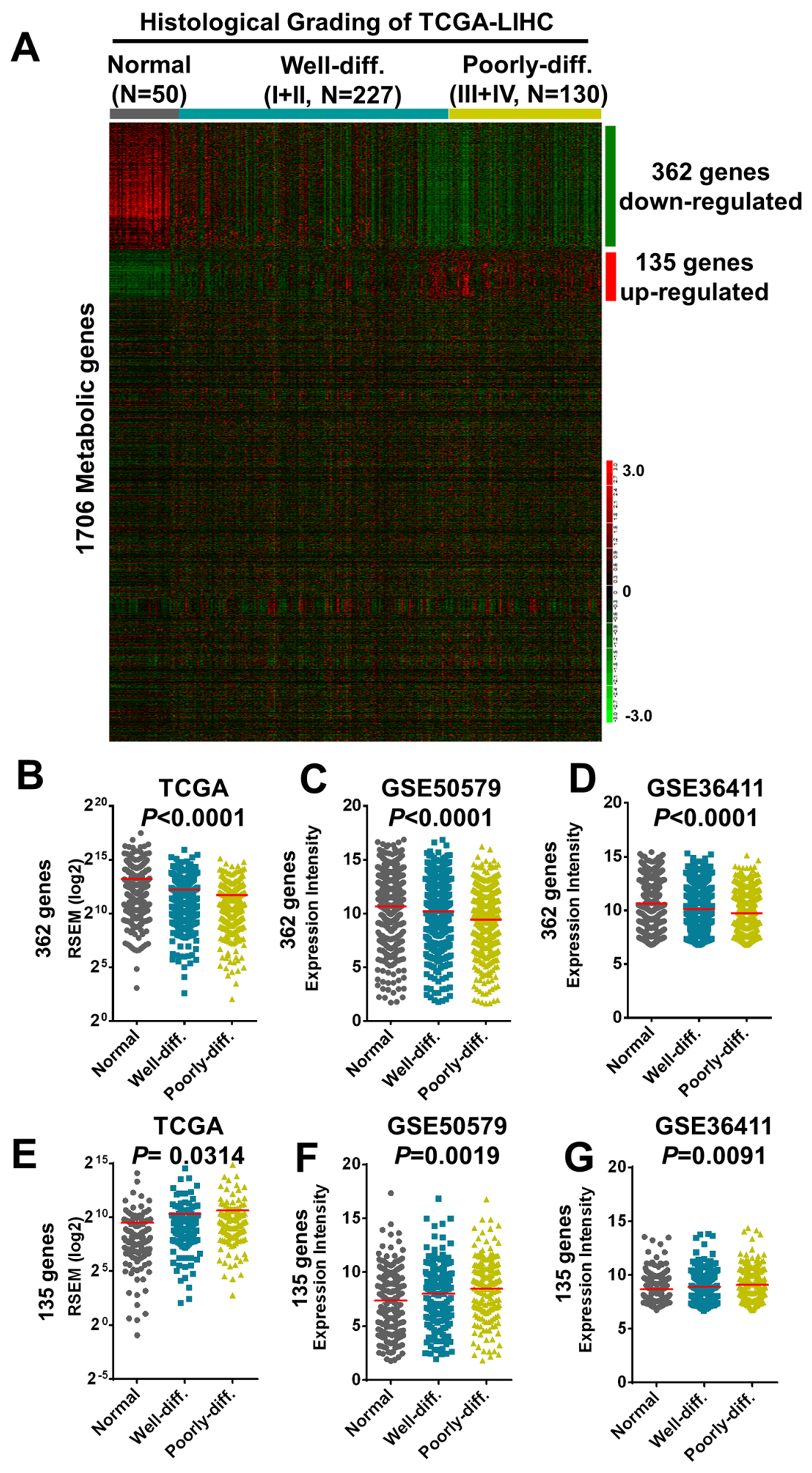

Figure 1: Transcriptomic correlations of 1706 metabolic genes with histological grading of human hepatocellular carcinoma in TCGA and microarray datasets. (A) A total of 497 including 362 downregulated and 135 upregulated genes were revealed after clustered with histological differentiation of HCC tumors as shown in the heatmap. (B-G) The 362 downregulated genes clustered with differentiation status of HCC tissues was shown in Sum RSEM of TCGA-LIHC (B) and validated by microarray datasets of GSE50579 (C) and GSE36411 (D). The135 upregulated genes were shown and validated in the same datasets (E-G), respectively. Statistical analysis was performed in one-way ANOVA. 

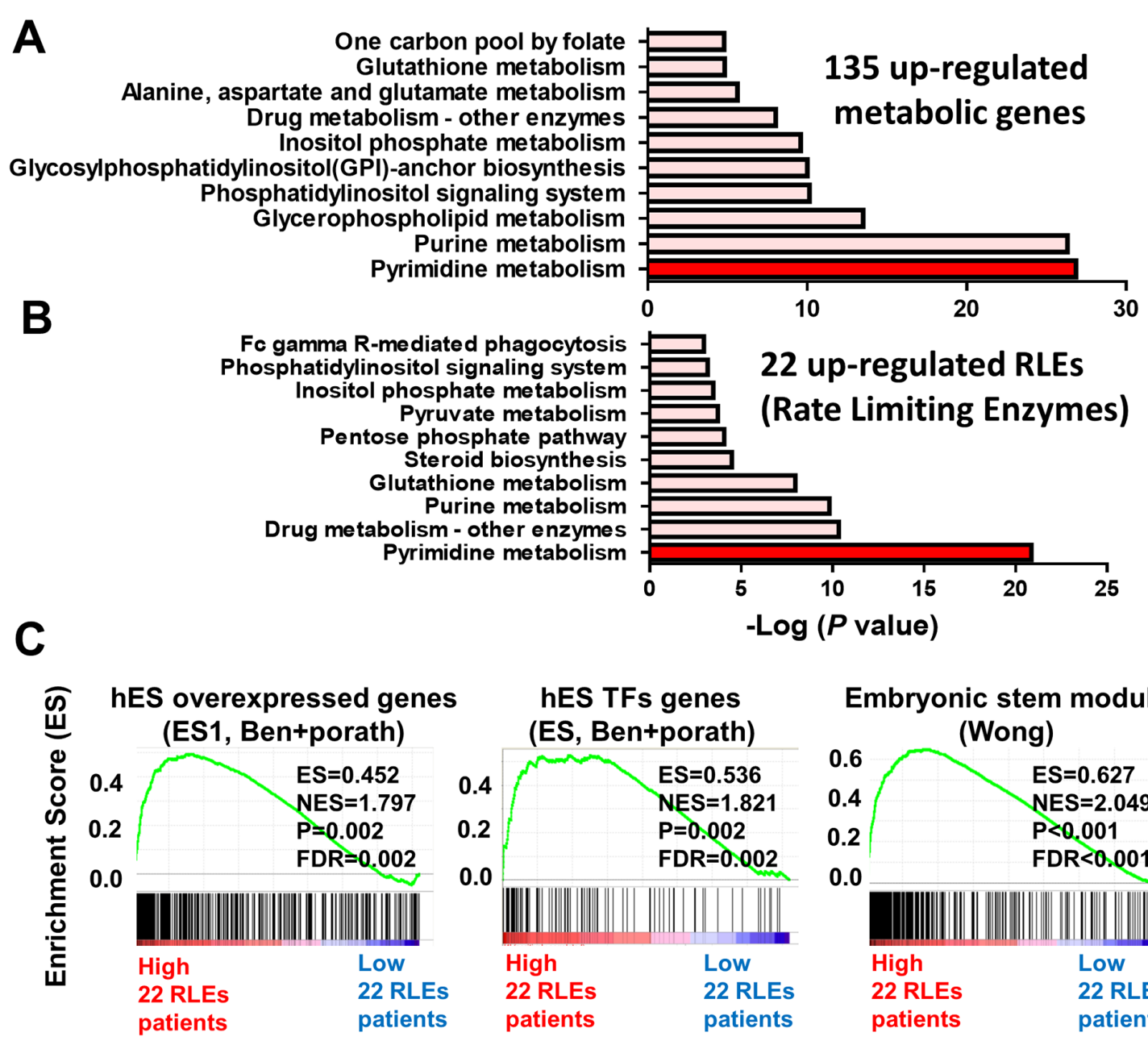

Embryonic stem module
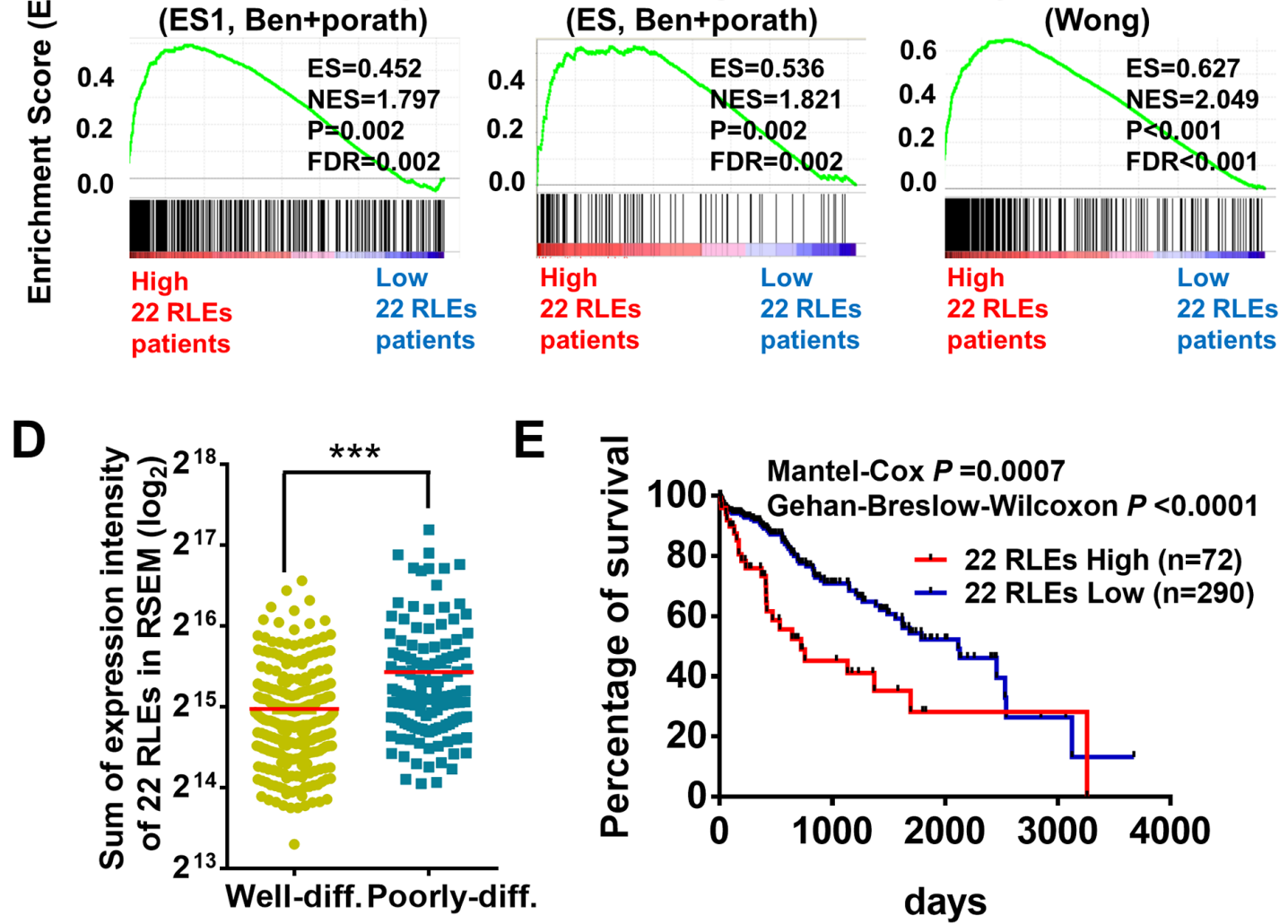

Figure 2: Functional prediction and prognostic value of upregulated metabolic enzymes in poorly-differentiated HCC. (A) 135 upregulated metabolic genes and (B) 22 rate limiting enzymes (RLEs) in the 135 metabolic genes were mainly enriched in pyrimidine metabolism performed in KEGG pathway analysis. (C) Upregulated expression of 22 RLEs were associated with stemness gene signatures by GSEA. (D) Sum expression intensity of 22 upregulated RLEs is higher in poorly-differentiated HCC than that of welldifferentiated HCC in TCGA-LIHC. (E) Higher expression of 22 upregulated RLEs is associated with poor survival of HCC patients in TCGA-LIHC. p value was calculated based on Mantel-Cox test and Gehan-Breslow-Wilcoxon test. $* * * p<0.0001$ performed by two-tailed Student's t-test. 


\begin{tabular}{|c|c|c|}
\hline & Metabolic pathways & Metabolic rate limiting enzymes \\
\hline \multirow[t]{2}{*}{ Nucleotides } & $\begin{array}{l}\text { PYRIMIDINE } \\
\text { METABOLISM }\end{array}$ & 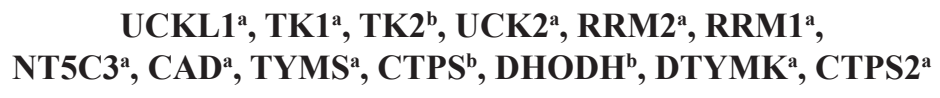 \\
\hline & PURINE_METABOLISM & $\mathrm{XDH}^{\mathrm{b}}, \mathrm{IMPDH}^{\mathrm{a}}, \mathrm{IMPDH}^{\mathrm{a}}, \mathrm{ADK}^{\mathrm{b}}$ \\
\hline \multirow[t]{8}{*}{ Lipid } & $\begin{array}{l}\text { FATTY_ACID_ } \\
\text { METABOLISM }\end{array}$ & 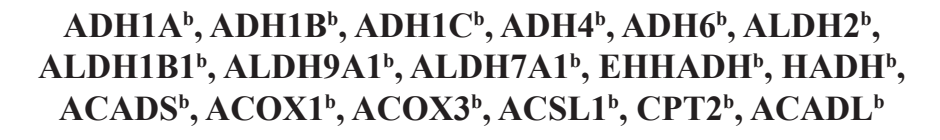 \\
\hline & $\begin{array}{l}\text { LINOLEIC_ACID_ } \\
\text { METABOLISM }\end{array}$ & PLA2G5 $^{\mathrm{b}}$, PLA2G12A $^{\mathrm{b}}$, CYP2J2 $^{\mathrm{b}}$ \\
\hline & $\begin{array}{l}\text { ARACHIDONIC_ACID_ } \\
\text { METABOLISM }\end{array}$ & GGT5 $^{\text {b }}$, PTGS2 ${ }^{\mathrm{b}}$ \\
\hline & $\begin{array}{l}\text { GLYCEROLIPID_- } \\
\text { METABOLISM }\end{array}$ & PPAP2B $^{\mathrm{b}}$, LIPC $^{\mathrm{b}}$, LIPG $^{\mathrm{b}}$ \\
\hline & $\begin{array}{l}\text { PRIMARY_BILE_ACID_ } \\
\text { BIOSYNTHESIS }\end{array}$ & HSD17B4 $^{\mathrm{b}}, \mathrm{CYP39A1}^{\mathrm{b}}$ \\
\hline & STEROID_BIOSYNTHESIS & LIPA $^{\mathrm{b}}, \mathrm{SQLE}^{\mathrm{a}}, \mathrm{SOAT2}^{\mathrm{a}}$ \\
\hline & $\begin{array}{l}\text { GLYCEROPHOSPHOLIPID_ } \\
\text { METABOLISM }\end{array}$ & GPD2 $^{\mathrm{a}}, \mathrm{BCHE}^{\mathrm{b}}$ \\
\hline & $\begin{array}{l}\text { STEROID_HORMONE_ } \\
\text { BIOSYNTHESIS }\end{array}$ & HSD17B6 $^{b}$ \\
\hline \multirow[t]{5}{*}{$\begin{array}{l}\text { Cofactors and } \\
\text { vitamins }\end{array}$} & FOLATE_BIOSYNTHESIS & PTS $^{b}$ \\
\hline & $\begin{array}{l}\text { VITAMINE_B6 } \\
\text { METABOLISM }\end{array}$ & PNPO $^{b}$ \\
\hline & $\begin{array}{l}\text { PORPHYRIN_AND_ } \\
\text { CHLOROPHYLL_- } \\
\text { METABOLISM }\end{array}$ & $\mathbf{A L A D}^{\mathrm{b}}$ \\
\hline & RETINOL_METABOLISM & 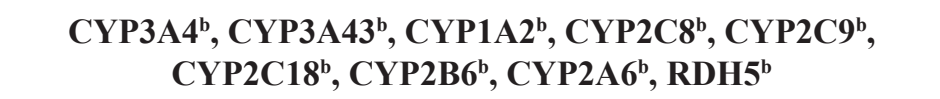 \\
\hline & $\begin{array}{l}\text { PANTOTHENATE_AND_ } \\
\text { COA_BIOSYNTHESIS }\end{array}$ & PANK1 $^{\mathrm{b}}$, PANK $^{\mathrm{b}}$ \\
\hline Xenobiotics & CAFFEINE_METABOLISM & NAT $^{\text {b }}$, NAT $^{\text {b }}$ \\
\hline \multirow[t]{6}{*}{ Carbohydrate } & $\begin{array}{l}\text { PROPANOATE } \\
\text { METABOLISM }\end{array}$ & ACACB $^{b}$, ACACA $^{a}$, SUCLA2 $^{b}$ \\
\hline & $\begin{array}{l}\text { PENTOSE_PHOSPHATE_ } \\
\text { PATHWAY }\end{array}$ & TKT $^{\mathrm{a}}$, G6PD $^{\mathrm{a}}$ \\
\hline & $\begin{array}{l}\text { GLYCOLYSIS } \\
\text { GLUCONEOGENESIS }\end{array}$ & DLD $^{\mathrm{b}}$, PCK2 $^{\mathrm{b}}$, PKM2 $^{\mathrm{a}}, \mathrm{FBP}^{\mathrm{b}}$ \\
\hline & $\begin{array}{l}\text { STARCH_AND_SUCROSE_ } \\
\text { METABOLSIM }\end{array}$ & GYS2 $^{\text {b }}$, PYGL $^{\mathrm{b}}$ \\
\hline & $\begin{array}{c}\text { AMINO_SUGARS_AND_ } \\
\text { NUCLEOTIDE_SUGARS_ } \\
\text { METABOLISM }\end{array}$ & GNE $^{\mathbf{b}}$ \\
\hline & $\begin{array}{l}\text { INOSITOL_PHOSPHATE_ } \\
\text { METABBOLISM }\end{array}$ & PIP5K1A $^{\mathrm{a}}$, PIP4K2B ${ }^{\mathrm{a}}$ \\
\hline
\end{tabular}




\begin{tabular}{|c|c|c|}
\hline & Metabolic pathways & Metabolic rate limiting enzymes \\
\hline Glycans & $\begin{array}{l}\text { OTHER_GLYCAN_- } \\
\text { DEGRADATION }\end{array}$ & MAN2B2 ${ }^{b}$ \\
\hline \multirow[t]{7}{*}{ Amino acids } & $\begin{array}{l}\text { VALINE_LEUCINE_- } \\
\text { AND_ISOLEUCINE_- } \\
\text { DEGRADATION }\end{array}$ & HMGCS2 $^{\mathrm{b}}, \mathrm{HSD} 17 \mathrm{~B} 10^{\mathrm{b}}, \mathrm{BCKDHA}^{\mathrm{b}}, \mathrm{BCKDHB}^{\mathrm{b}}$ \\
\hline & $\begin{array}{l}\text { TRYPTOPHAN_ } \\
\text { METABOLISM }\end{array}$ & $\mathrm{OGDHL}^{\mathrm{b}}, \mathrm{IDO}^{\mathrm{b}}, \mathrm{TDO}^{\mathrm{b}}, \mathrm{KMO}^{\mathrm{b}}$ \\
\hline & TYROSINE_METABOLISM & TAT $^{\mathbf{b}}$ \\
\hline & $\begin{array}{c}\text { ARGININE_AND_PROLINE_ } \\
\text { METABOLISM }\end{array}$ & GATM $^{\mathrm{b}}$, SAT1 $^{\text {b }}$ \\
\hline & $\begin{array}{l}\text { GLYCINE_SERINE_AND_ } \\
\text { THREONINE_METABOLISM }\end{array}$ & $\mathrm{CBS}^{\mathrm{b}}$, ALAS1 $^{\mathrm{b}}$ \\
\hline & $\begin{array}{l}\text { PHENYLALANINE_ } \\
\text { METABOLISM }\end{array}$ & $\mathbf{P A H}^{\mathbf{b}}$ \\
\hline & $\begin{array}{l}\text { GLUTATHIONE_- } \\
\text { METABOLISM }\end{array}$ & GSTZ1 $^{\mathrm{b}}$, MGST1 $^{\mathrm{b}}$, MGST2 $^{\mathrm{b}}, \mathrm{SRM}^{\mathrm{a}}$ \\
\hline
\end{tabular}

a: up-regulated RLEs; b: down-regulated RLEs.

No matter the GSEA comparisons were performed in between genes in groups of poorly-differentiated versus well-differentiated HCC ( Supplementary Figure 2A), highly expressed and lowly expressed 22 upregulated RLEs (Figure 2C and Supplementary Figure 2B), and highly expressed and lowly expressed 77 downregulated RLEs (Supplementary Figure $1 \mathrm{C}$ and 2C), we found that aberrant gene expression including the metabolic RLEs in poorly-differentiated $\mathrm{HCC}$ are strongly correlated with gene signatures of embryonic stem (ES) module [27], human ES cell overexpressed genes and TFs (transcription factors) [28] and proliferation-enhanced G2M checkpoints [29] (Supplementary Figure 2A-2C). These embryonic stemness gene sets were commonly enriched and shared in cancer cells with stemness features and tumor aggressiveness. In contrast, these aberrant metabolic enzymes in poorlydifferentiated HCC do not correlate with gene signatures of apoptosis, EMT, hypoxia and inflammatory response (Supplementary Figure 2A and 2C).

We also found that sum of the expression intensity of 22 upregulated RLEs were significantly upregulated in poorly-differentiated HCC than that in well-differentiated HCC in TCGA-LIHC (Figure 2D). On the other hand, the 77 downregulated RLEs were significantly downregulated in poorly-differentiated HCC than that in well-differentiated HCC in TCGA-LIHC datasets (Supplementary Figure 1D). Moreover, when re-classified HCC patients with high RLE score (the sum of all RLE expression value), 77 downregulated RLEs and 22 upregulated RLEs, we found HCC patients grouping with these aberrant RLE expression were associated with poor survival in TCGA-LIHC (Supplementary Figures 1E and $3 \mathrm{~A}$, Figure 2E).

Concordant expression of 99 RLEs and of stemness markers in TCGA-LIHC and six HCC cell lines are correlated with $\mathrm{HCC}$ differentiation

To obtain HCC cell lines with histological differentiation status for functional validation, we downloaded RNA transcriptomic data of six HCC cell lines with known differentiation status, welldifferentiated HCC (PLC5, HepG2 and Hep3B) and poorly-differentiated HCC (SNU387, SNU449 and SkHep1) cell lines, from the cancer cell line encyclopedia (CCLE) project. We found high similarity in clusters of the average expression intensity of 99 RLEs expression in compared between TCGA and 6 HCC cell lines by grouping with their differentiation status (Figure $3 \mathrm{~A})$. Moreover, we characterized cell morphology and known stem cell markers CD44 [30] and CD90 [31] for confirming their differentiation status. Our results showed that PLC5, HepG2 and Hep3B with epithelial morphology and low $\mathrm{CD} 44 / \mathrm{CD} 90$ expression were validated as welldifferentiated HCC cells (Figure 3B), whereas SNU387, SNU449 and SK-Hep1 with spindle shape phenotype and high CD44/CD90 expression were confirmed as poorlydifferentiated HCC cells (Figure 3C). The associations of 22 upregulated RLEs and 77 downregulated RLEs with high expression of HCC stemness marker CD44 expression were validated in HCC samples of TCGALIHC cohort (Supplementary Figure 3B). 


\section{Expression of 10 upregulated RLEs in pyrimidine metabolism pathway are increased in cancer stem cell populations}

Since pyrimidine metabolism was the most enriched pathway in 22 upregulated RLEs in poorly-differentiated $\mathrm{HCC}$ with potential prognostic value, we further investigate the expression of 10 RLEs in pyrimidine pathway in stemness population of HCC cells. Firstly, we reclassified HCC patients in TCGA-LIHC with 10 upregulated RLEs in pyrimidine pathway and validated their associations with known stemness signatures by GSEA (Figure 4A). Owing to very low percentage of $\mathrm{CD} 44^{+}$and $\mathrm{CD} 90^{+}$cell populations in well-differentiated HCC cells (Figure 3B), we isolated cancer stemness sub-populations with the most conservative cancer stemness marker ALDH1 from HepG2 and SNU449 for analysis the expression of 10 RLEs. Our results showed that expression of 10 RLEs of pyrimidine pathway and the relative dTTP concentration were significantly upregulated in ALDH1 positive populations in compared with ALDH1 negative populations of HepG2 (Figure 4B) and SNU449 (Figure 4C) with possibility to participate in cancer stemness properties.

\section{Three upregulated RLEs in the dTTP biosynthesis of pyrimidine metabolism pathway are essential for stemness and increased cellular dTTP}

Among 10 pyrimidine metabolism enzymes, three RLEs including thymidine kinase (TK1), thymidylate synthetase (TYMS) and deoxythymidylate kinase (DTYMK) were critical for dTTP biosynthesis (Figure 5A). Expression of 3 RLEs in dTTP biosynthesis and the cellular dTTP concentration were higher in poorlydifferentiated HCC, Sk-Hep1 and SNU449, than that in well-differentiated HCC, PLC5 and Hep3B by Western blotting and dTTP concentration analysis respectively (Figure 5B and 5C). As shown in our knockdown efficiencies of TK1, TYMS and DTYMK at protein level with shRNAs, we demonstrated that knockdown either one of the 3 RLEs in dTTP biosynthesis pathway decreased the protein expression and the cellular concentration of dTTP in poorly-differentiated HCC cells Sk-Hep1 and SNU449 (Figure 5D and 5E).

\section{Knockdown 3 RLEs decreased tumor sphere formation, ALDH1 ${ }^{+}$sub-populations and drug resistance to cisplatin treatments}

To examine the participation of 3 RLEs in HCC stemness features, we found that the expression of TK1, TYMS and DTYMK is higher in ALDH1 positive population than that of ALDH1 negative population in HCC cells by Western blotting analysis (Figure 6A). Knockdown of TK1, TYMS and DTYMK reduced capability of forming tumor spheroids as shown in results of microscopy (Figure 6B) and in assays of 2 serial passages (Figure 6C). Moreover, knocking down TK1, TYMS and DTYMK reduce population size of ALDH1 positive cells by ALDHflour analysis (Figure 6D) and resistance to cisplatin treatments in in poorly-differentiated HCC cells (Figure 6E).

\section{Overexpression of TK1, TYMS and DTYMK increased tumor stemness features and associated with poor HCC patient survival}

To further explore the roles of the 3 upregulatedRLEs of dTTP biosynthesis in enhancing stemness features and accompanied with prognostic value, we overexpressed TK1, TYMS and DTYMK in welldifferentiated HCC cells PLC5 and Hep3B (Figure 7A). we found that expression of TK1, TYMS and DTYMK enhanced tumor sphere formation capability (Figure 7B and $7 \mathrm{C}$ ) and increased ALDH1 positive populations in well-differentiated HCC cells (Figure 7D).

Moreover, HCC patients with higher expression of TK1, TYMS and DTYMK at RNA level have poor survival rates in compared to patients with lower expression of 3 RLEs in 362 patients from TCGALIHC (Figure 8A). The prognostic value of these 3 upregulated RLEs of dTTP biosynthesis at RNA level expression was further confirmed with $110 \mathrm{HCC}$ patients in Taiwan collected by the Taiwan liver cancer network (TLCN) project [32] (Figure 8B). The prognostic value of 3 upregulated RLEs TK1, TYMS and DTYMK in HCC patients were further confirmed at protein level by performing immunohistochemistry (IHC) on commercial HCC tissue arrays (Figure 8C). Our results of upregulated TK1, TYMS and DTYMK in HCC tumors at RNA and protein levels in multiple independent HCC cohorts further suggested that pyrimidine metabolism especially dTTP biosynthesis pathway is upregulated in poorlydifferentiated HCC cells to sustain cancer stemness resulted in poor survival of HCC patients.

\section{DISCUSSION}

To uncover new theranostic targets of HCC, we investigate the roles of tumor metabolism in the lethal aggressive stage, the poorly-differentiated feature in the case of HCC, for exploring the molecular mechanism of tumor malignancy. Through transcriptomic analysis of metabolic enzymes in large HCC cohorts including the RNA-seq data from public TCGA-LIHC and two independent gene expression data based on microarray platforms in GEO, we identified a unique metabolic mRNA signature and candidate cancer genes consisting of 22 upregulated RLEs and 77 downregulated RLEs in poorlydifferentiated HCC associated with stemness and poor patient survival. With correlation of expression profiling of 
A

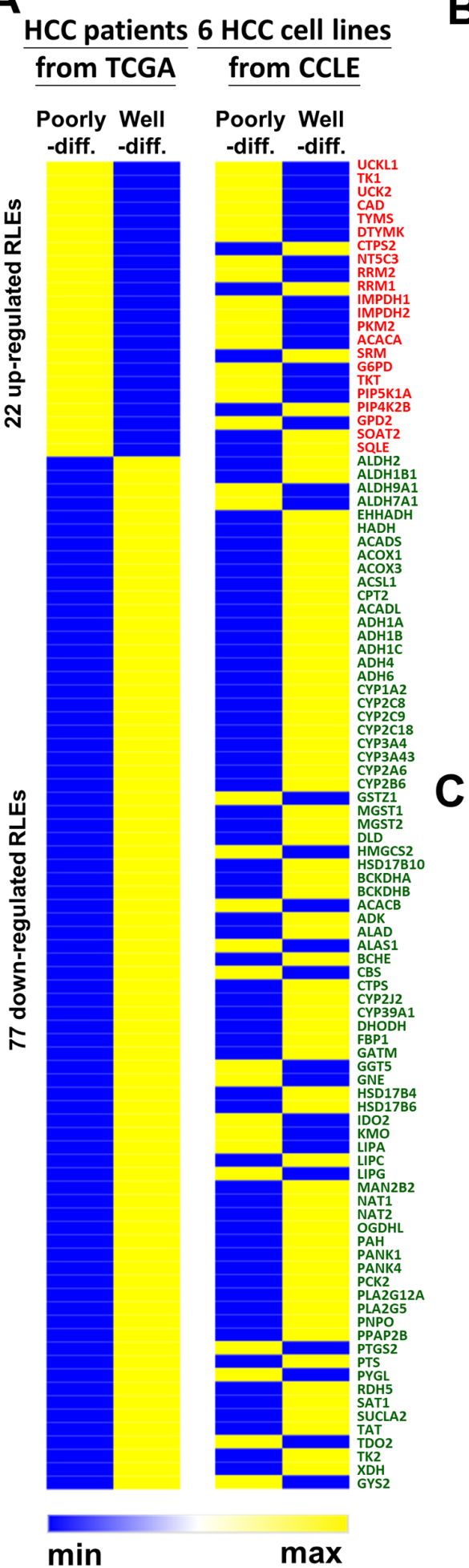

B
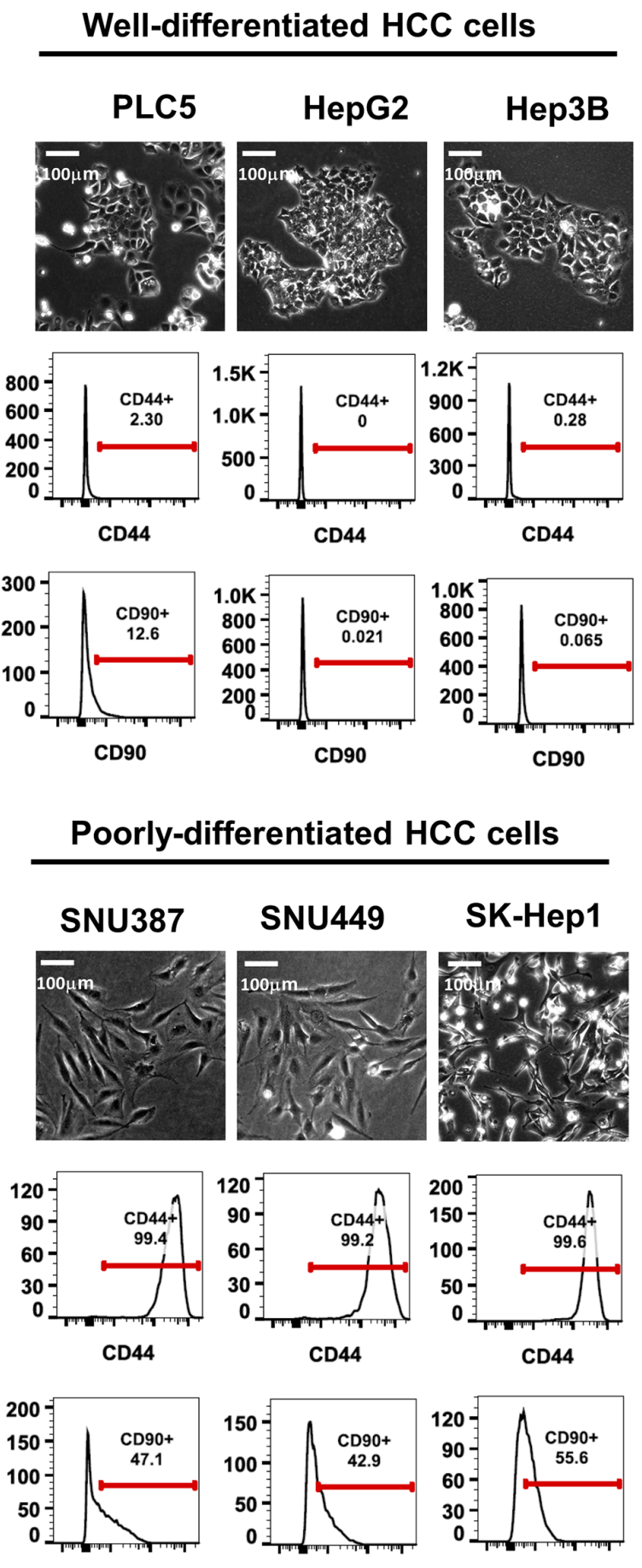

CD90

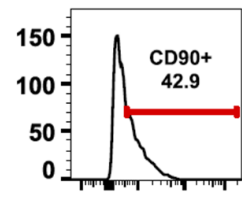

CD90

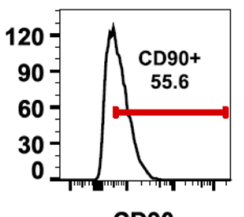

CD90

Figure 3: Concordant expression of 99 RLEs and of stemness markers in TCGA-LIHC and six HCC cell lines are correlated with HCC differentiation. (A) Heatmap clusters of average expression intensity of 99 RLEs in TCGA-LIHC and six HCC cell lines in CCLE. (B and C) Cell morphology and expression status of stemness markers CD44 and CD90 in compared with IgG antibody by FACS analysis (B) in well-differentiated HCC cell lines and (C) in poorly-differentiated HCC cell lines. Red lines stand for the gating ranges of CD44+ or CD90+ cells. The numbers under CD44 or CD90 indicates the percentage of cells show positive of CD44 or CD90 in particular HCC cell. 
A
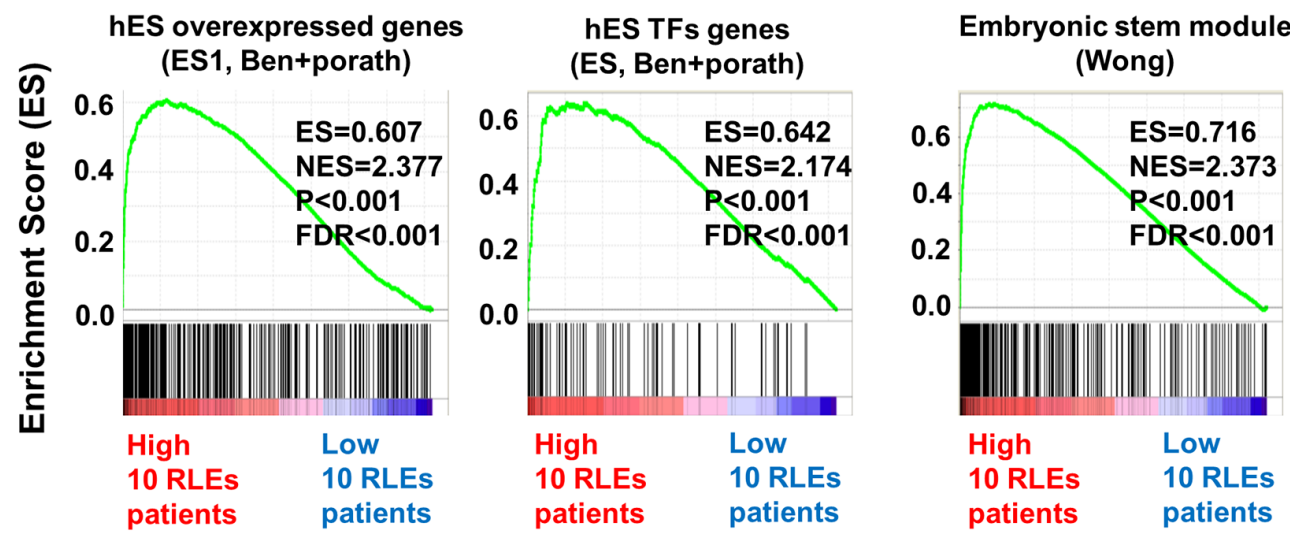

B HepG2

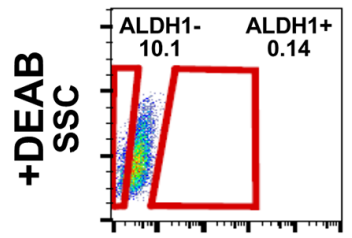

ALDH1
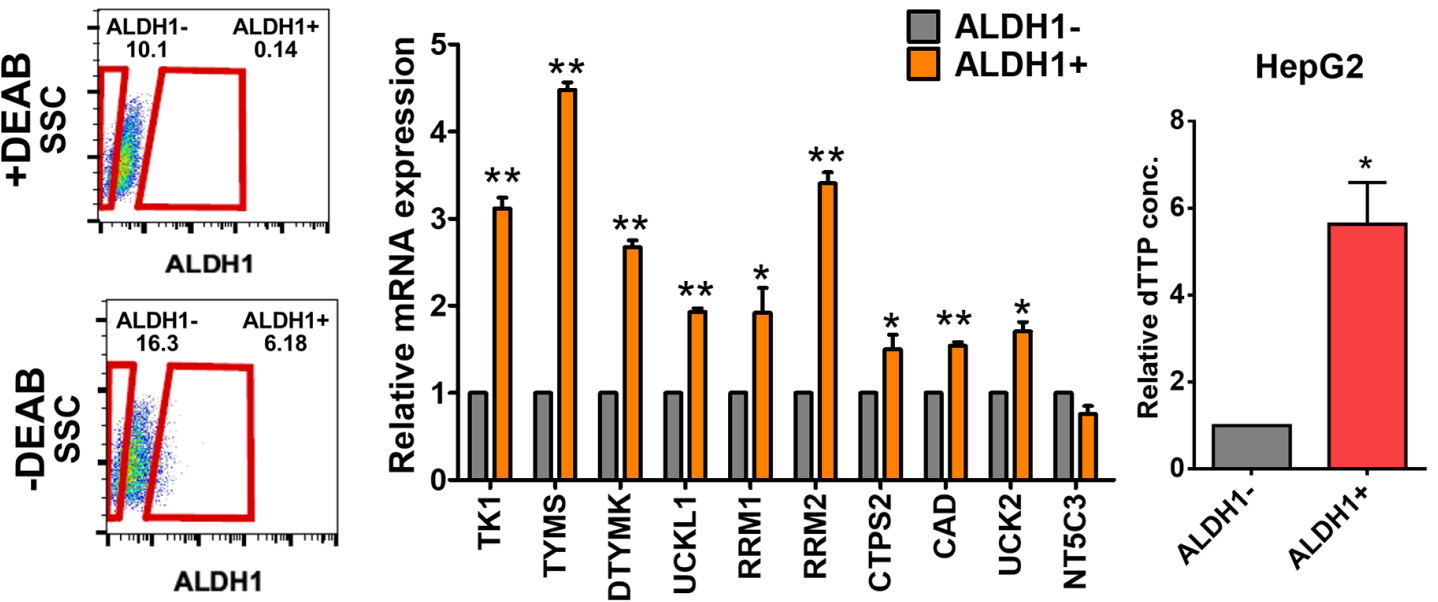

C
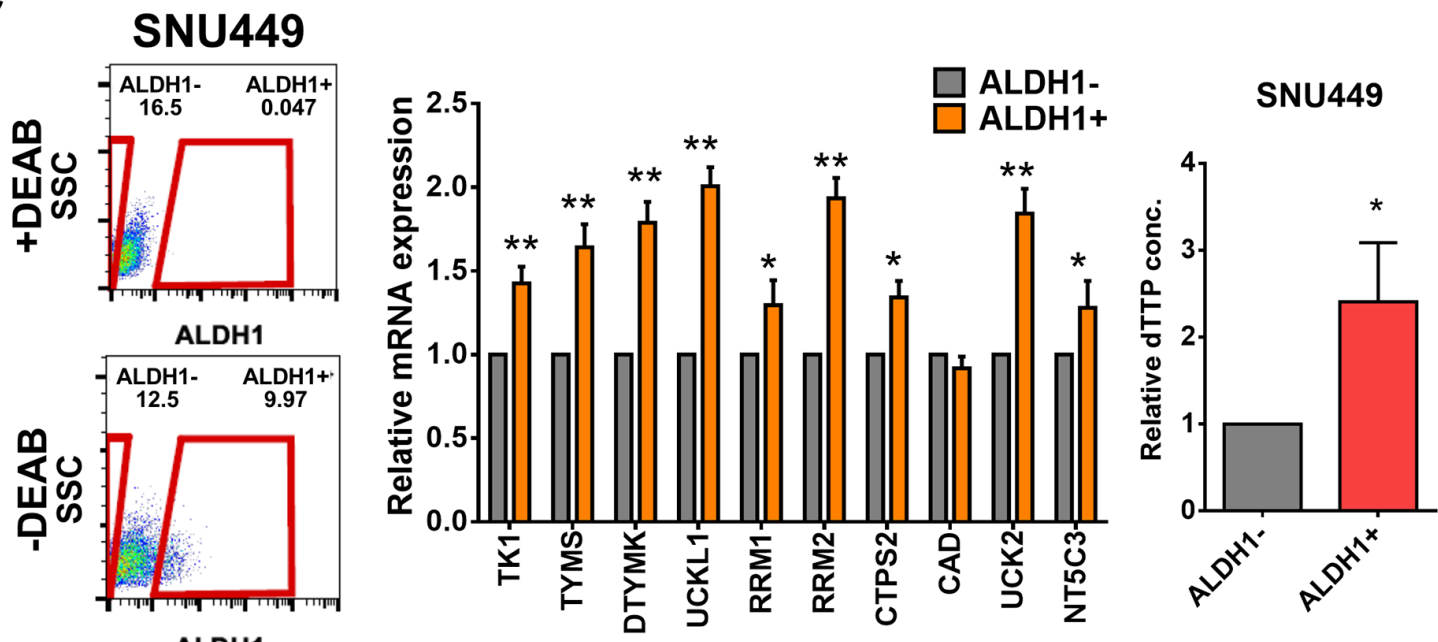

Figure 4: Expression of 10 upregulated RLEs in pyrimidine metabolism in ALDH1 positive stemness sub-populations of HCC cell lines. (A) Up-regulated expression of 10 RLEs were associated with stemness gene signatures by GSEA. (B-C) Higher expression of 10 up-regulated RLEs and relative high dTTP concentration were shown in ALDH1 positive sub-populations than that of ALDH1 negative sub-populations in HepG2 (B) and SNU449 (C) HCC cells. Red boxes indicated the measured areas of ALDH1- or ALDH1 + cell populations. The numbers indicated the percentage of ALDH1- and ALDH1+ population occupied in a given HCC cell in the experiment. ${ }^{*} \mathrm{P} \leq 0.05$ and ${ }^{* *} \mathrm{P} \leq 0.001$ performed by two-tailed Student's t-test. 


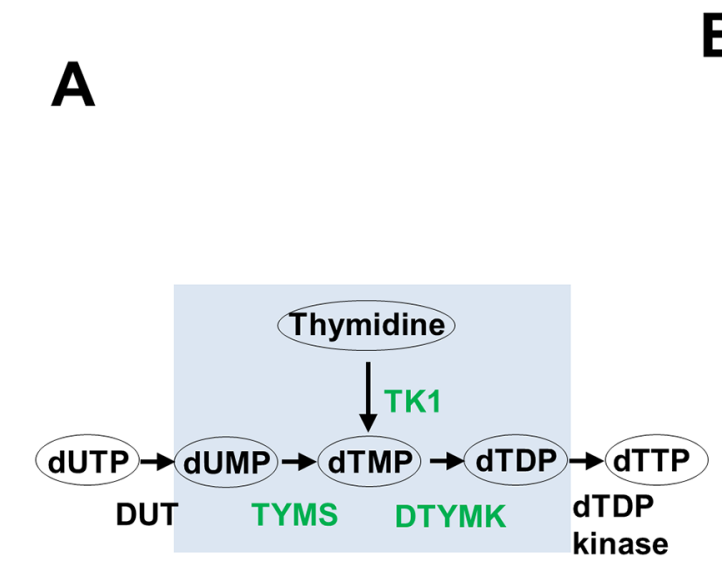

B
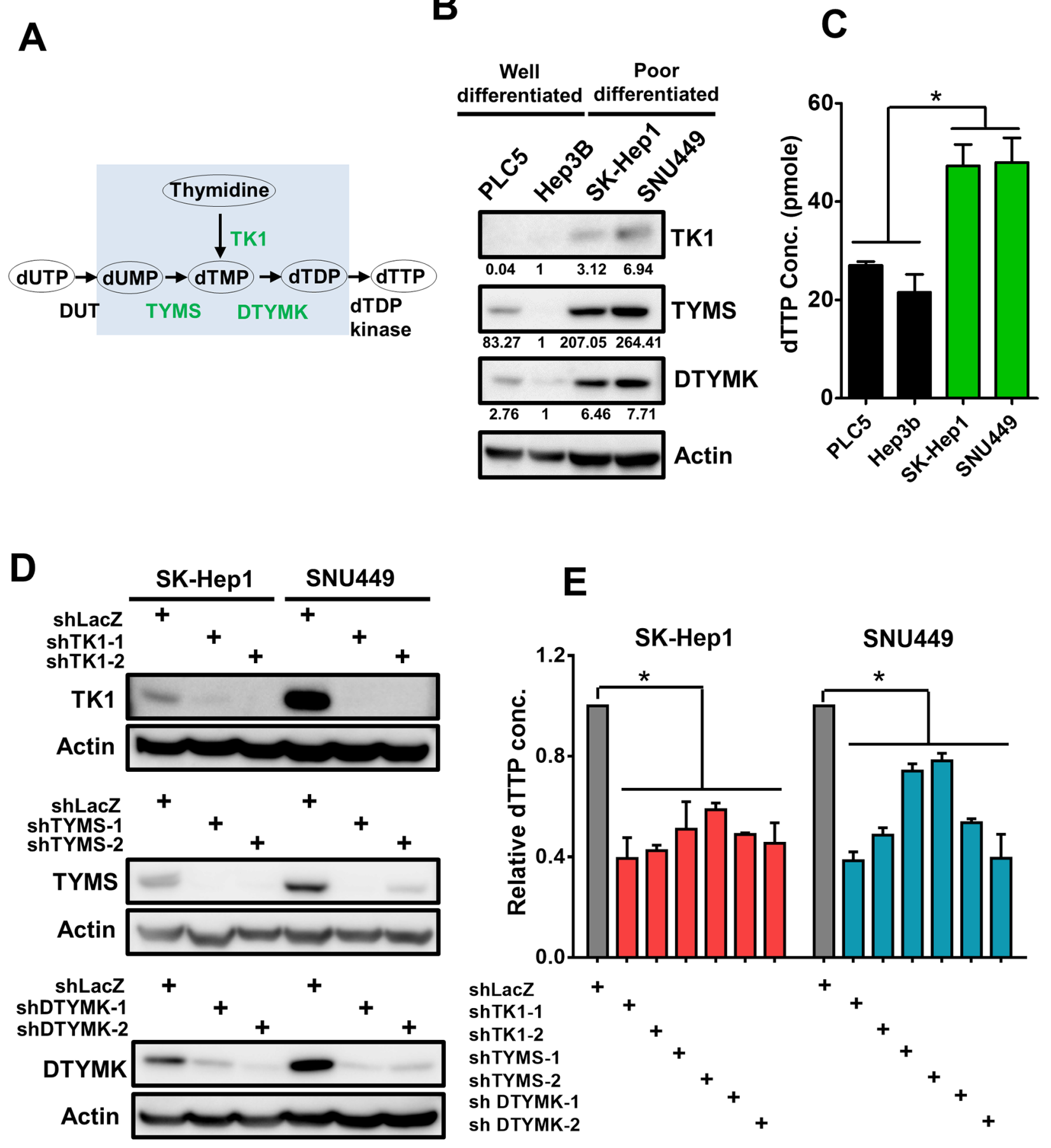

Figure 5: Up-regulated 3 RLEs TK1, TYMS and DTYMK are critical for sustaining cellular dTTP concentration. (A) TK1, TYMS and DTYMK are rate-limiting enzymes for de novo dTTP synthesis. (B) TK1, TYMS and DTYMK are expressed higher in poorly-differentiated than that of well-differentiated HCC cells by Western blotting analysis. The intensity value under a band is normalized to the intensity of actin of the same cell and then divided by Hep3B intensity of the same RLE for comparison. (C) Higher concentration of dTTP in poorly-differentiated than that of well-differentiated HCC cells. (D) Knockdown efficiency of shRNAs to TK1, TYMS and DTYMK in HCC cells by Western blotting analysis. (E) Knockdown TK1, TYMS and DTYMK reduced relative dTTP concentration in poorly-differentiated HCC cells. 

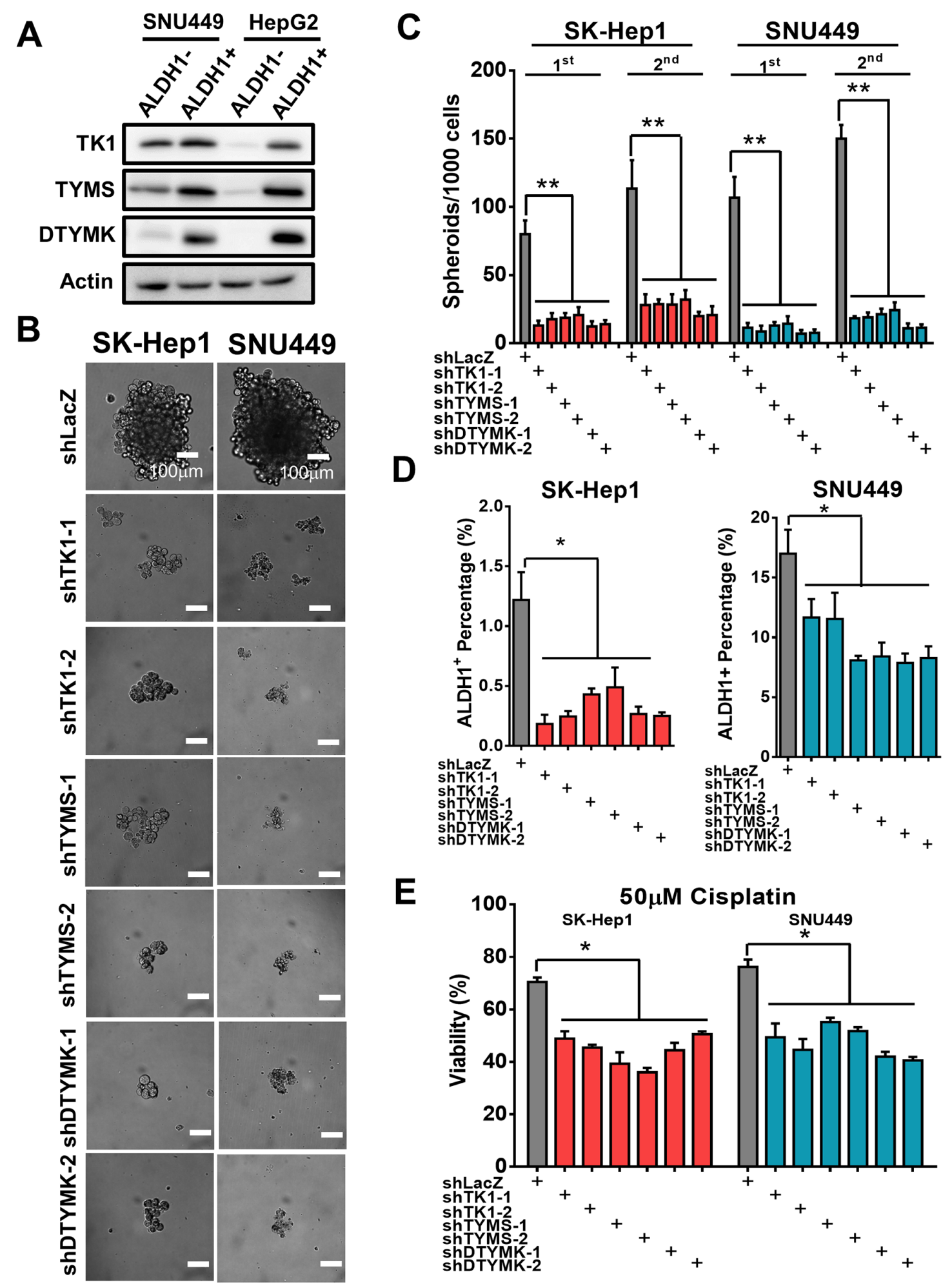

Figure 6: Knockdown TK1, TYMS and DTYMK decreased tumor sphere formation, ALDH1 positive sub-populations and drug resistance. (A) Higher expression of TK1, TYMS and DTYMK in ALDH1 positive than that of ALDH1 negative HCC cells by Western blotting analysis. (B) Knockdown TK1, TYMS and DTYMK reduced spheroids formation ability. (C) Knockdown TK1, TYMS and DTYMK reduced tumor spheroid formation in 2 serial passages. (D) Knockdown TK1, TYMS and DTYMK reduced expression of ALDH1 stemness subpopulations by ALDHflour analysis. (E) Knockdown TK1, TYMS and DTYMK decreased drug resistance to cisplatin treatments. 
A
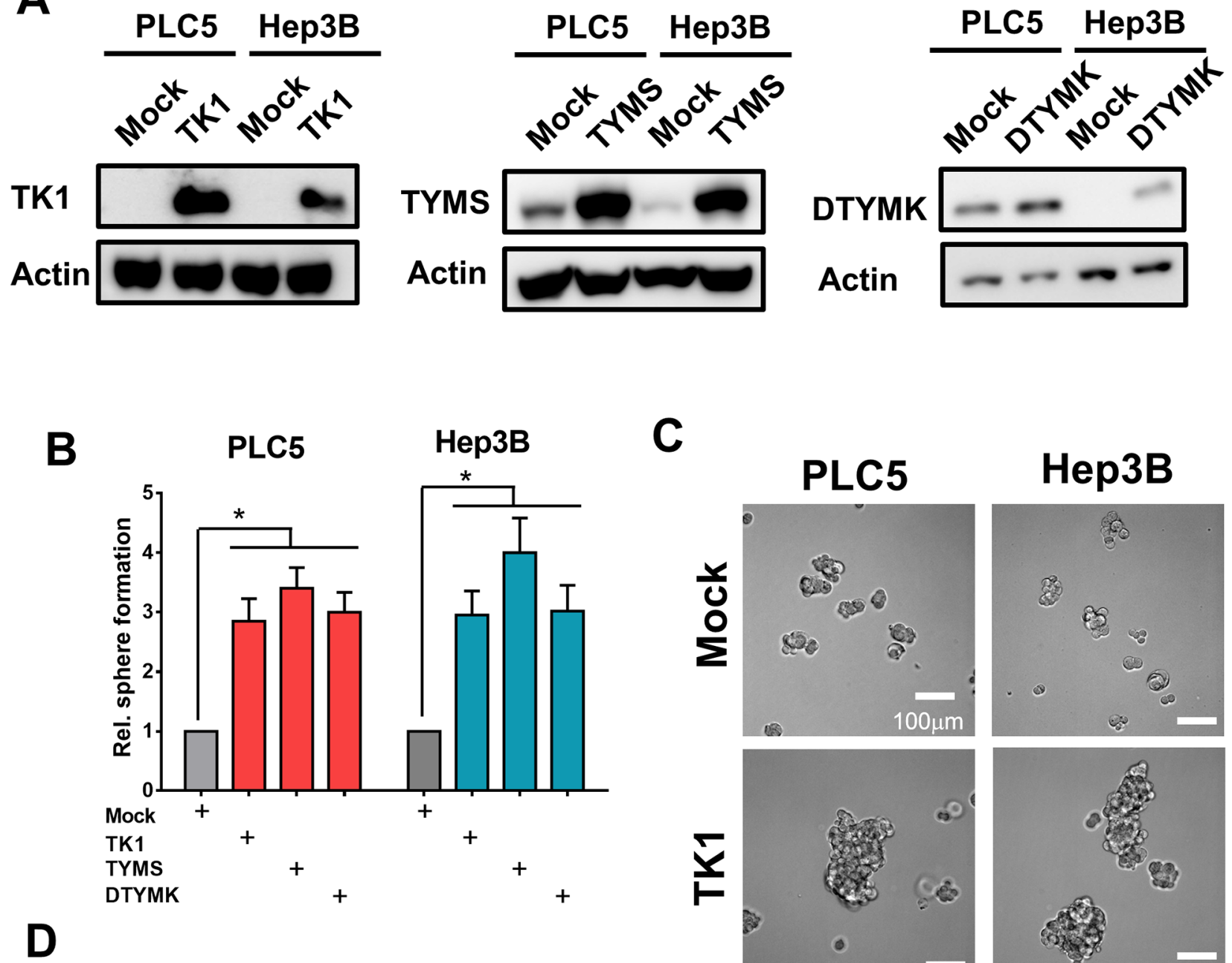

C

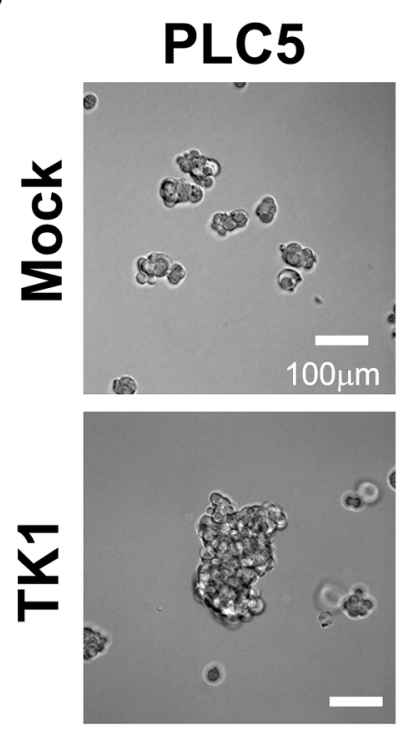

Hep3B
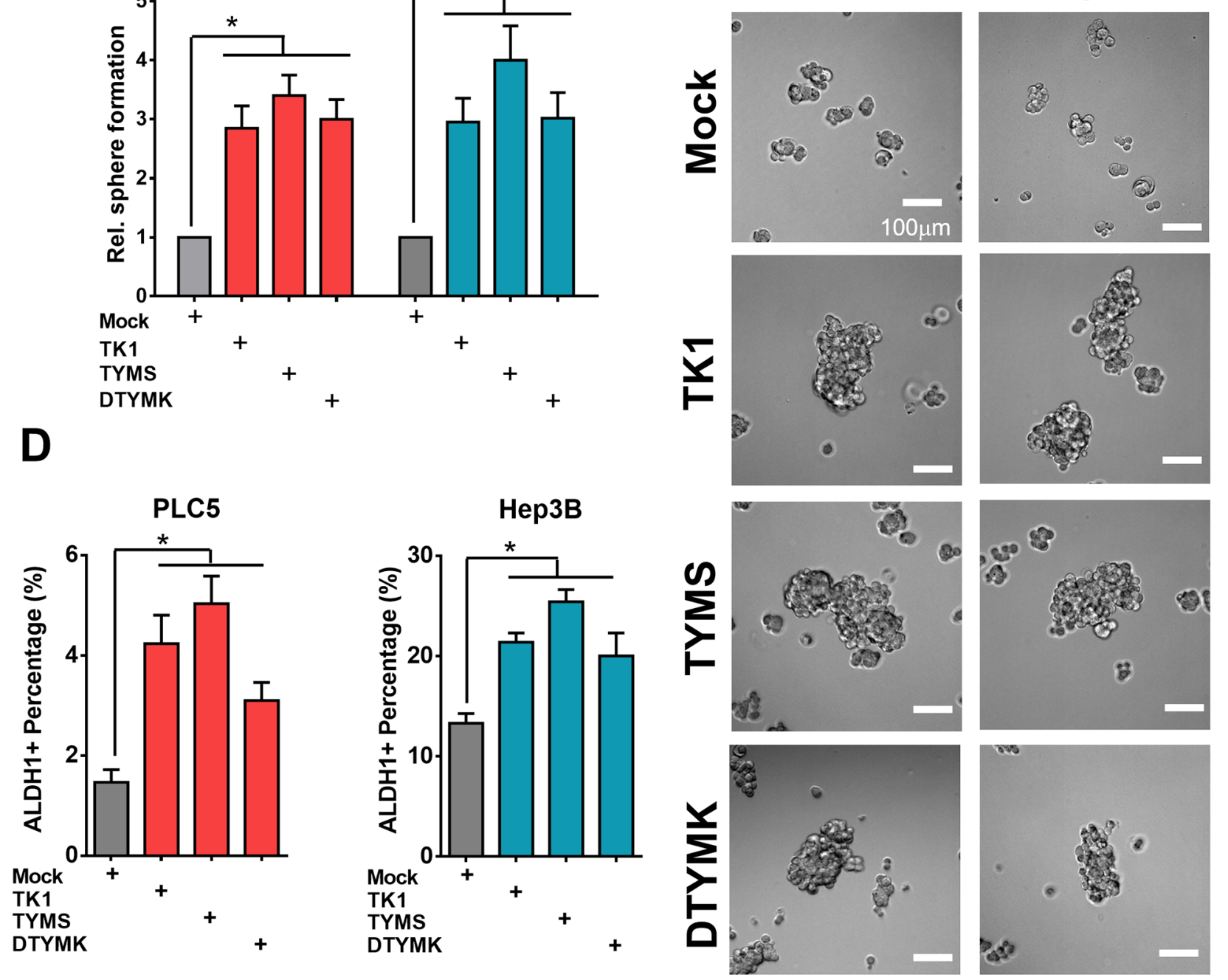

Figure 7: Overexpression of TK1, TYMS and DTYMK increased tumor sphere formation and ALDH1 positive sub-populations. (A) Overexpression efficiency of TK1, TYMS and DTYMK in HCC cells by Western blotting analysis. (B and C) Overexpression of TK1, TYMS and DTYMK increased spheroids formation ability. (D) Overexpression of TK1, TYMS and DTYMK increased expression of ALDH1 positive stemness subpopulations. 
metabolic RLEs and differentiation status of TCGA-LIHC and HCC cell lines, we revealed that upregulated RLEs in pyrimidine metabolism especially the 3 RLEs (TK1, TYMS and DTYMK) of dTTP biosynthesis pathway play critical roles in increasing cellular dTTP concentration and sustaining the stemness properties. Upregulated 3 RLEs associated with cancer stemness features might participate in the poor differentiation feature in tumor progression and associate with poor survival of HCC patients.

The major advantage of our integrated genomic approach is to focusing on the aberrant roles of metabolic enzymes in poorly-differentiated HCC and their tumor progression. Consistent with previous tissue metabolomics of high-grade (poorly-differentiated) versus low-grade (well-differentiated) HCC by using NMR spectroscopy, the high-grade HCC showed the increase of lactate, glutamate and alanine and lower levels of lipid, glucose and glycogen in compared with the low-grade HCC [33]. The outcomes of these altered metabolites in high-grade HCC might have resulted from the decrease of RLEs in the amino acid degradation and lipid metabolism and the increase of RLEs in the pyruvate and nucleotide metabolism (Table 1). Our study confirmed the roles of alteration of energy metabolism in HCC histological grading and revealed a novel role of pyrimidine metabolism in supporting stemness and malignant progression of HCC.

The focus of altered metabolism in tumor progression is an emerging field for uncovering new driver genes to target cancer metastasis in recent years. Although previous studies of increased de novo lipogenesis pathway could promote HCC tumorigenesis [34-36], interestingly, recent study to inhibit hepatic lipogenesis by liver-specific knockout of acetyl-CoA carboxylase (ACC) could enhance liver tumorigenesis by increasing antioxidant defense and promoting cell survival [37]. Moreover, high unsaturated lipids were enriched in cancer stem-like cells (CSCs) than that of non-CSC and required for supporting ovarian CSC [38]. Our result of decreased lipid metabolism in

A

TCGA-LIHC
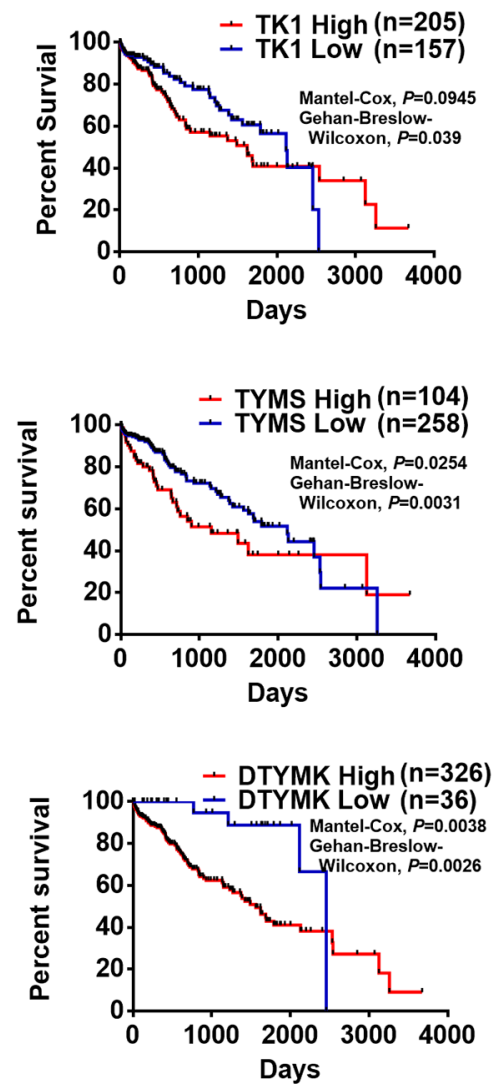

B

\section{HCC-TLCN}
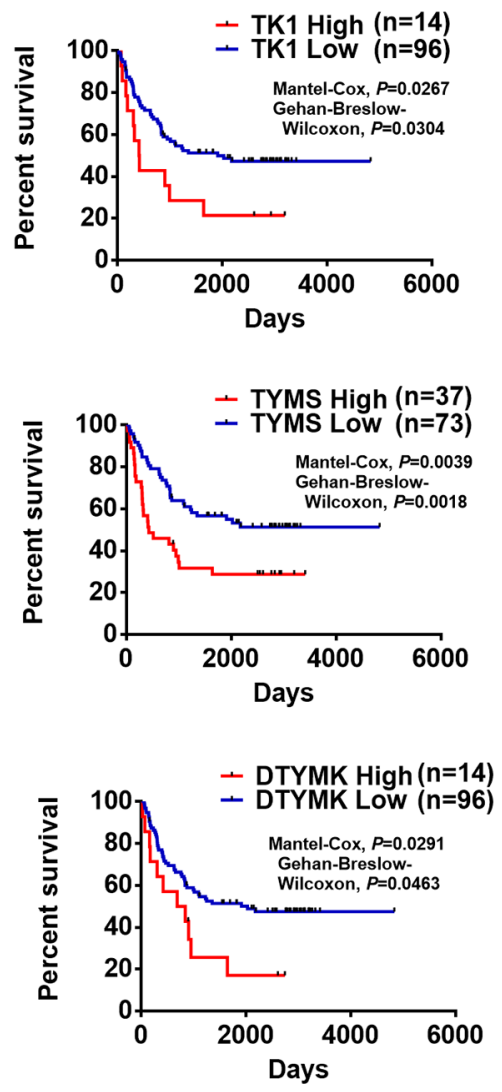

C
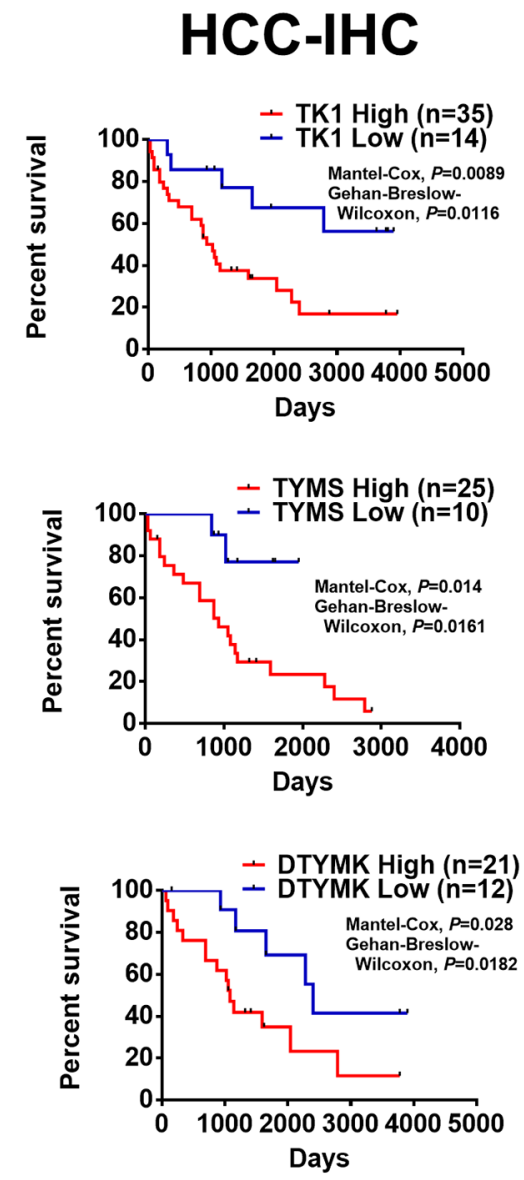

Figure 8: Higher expression of TK1, TYMS and DTYMK is associated with poor patient survival of HCC patients. Upregulated TK1, TYMS and DTYMK at RNA level of (A) TCGA-LIHC and (B) HCC-TLCN (Taiwan liver cancer network), and (C) at protein level from HCC tissue arrays by IHC staining (HCC-IHC) are associated with poor HCC patient survival. 
association with poor HCC survival is consistent with these recent reports. Nevertheless, another obvious alteration of pyrimidine metabolism pathway in poorly-differentiated HCC for sustaining stemness and association with poor HCC patient survival was never been revealed in previous cancer metabolic studies. Interestingly, approximately half of the 22 upregulated RLEs is involved in pyrimidine pathway, a major contributor to DNA and RNA nucleotide synthesis, to participate in the poorly-differentiated feature, stemness and poor prognosis of HCC.

In the de novo pyrimidine pathway, 3 RLEs including TYMS (Thymidylate Synthetase), DTYMK (Deoxythymidylate kinase) and TK1 (Thymidine kinase 1) play critical roles in the dTTP biosynthesis. TYMS, a key rate-limiting enzyme in the folate metabolism, plays essential roles in the development of several malignancies such as prostate cancer and lung cancer [39, 40]. Inhibition of TYMS by treatment with cancer chemotherapy drug 5-FU (5-Fluorouracil) results in accumulation of FdUMP, which might subsequently lead to increased levels of fluoro-deoxyuridine triphosphate (FdUTP) [41]. DNA damage due to FdUTP mis-incorporation results in DNA strand breaks and cancer cell death. DTYMK catalyzes dTTP biosynthesis as synthetically lethal with $1 \mathrm{~kb} 1$ deficiency in mouse and human lung cancer lines [42]. TK1 catalyzes the conversion of thymidine to deoxythymidine monophosphate (dTMP) is function as a proliferation marker in multiple cancer types. In our study, we found that TYMS, TK1 and DTYMK are enriched in ALDH1+ population and knockdown either one of these RLEs decreased ALDH1+ population in poor-differentiated HCC SK-Hep1 and SNU449 cells. Interestingly, upregulation of TYMS and DTYMK was observed in the 5-FU resistant colon cancer cells [43]. Our results of these dTTP biosynthesis RLEs involved in cancer stemness might provide new strategies for 5-FU combination therapeutic modalities for improvement of advanced HCC therapy.

Although cancer metabolism could be influent by intrinsic and extrinsic factors in the tumor microenvironment, understanding metabolic regulation of CSCs might offer new promising approaches for identifying and targeting recalcitrant stem cell populations. CSCs are small but significant populations of cancer cells with self-renewal and tumor-initiating properties. CSCs are known to increase intra-tumoral heterogeneity and drug resistance resulted in disease progression, recurrence, metastasis and adverse patient outcomes [44]. In this study, we revealed pyrimidine metabolic enzymes required for supporting CSC and associated with poor survival of $\mathrm{HCC}$ is clinically relevant because many of the enzymes have well-defined active sites that can potentially be targeted by small molecules. Future studies of underlining mechanisms on the metabolic reprogramming of pyrimidine pathway in CSCs and development of drugs to target pyrimidine RLEs should be critical for CSC- targeting therapies with the ultimate goal of overcoming tumor relapse and metastasis.

\section{EXPERIMENTAL PROCEDURES}

\section{RNA preparation and quantitative reversed transcription PCR (RT-qPCR)}

Total cellular RNA was extracted using Trizol reagent (Invitrogen) according to the manufacturer's procedures for RT-PCR. Quantitative RT-PCR was performed by SYBR Green Master Mix (Applied Biosystems) according to the manufacturer's protocols. The specific primers used in RT-qPCR are shown below: hCAD Forward primer (F) 5' CCCGCAGGAGGACACCTATG, Reversed primer (R) 5' CGGTGCCCTTCACTTTCTGC; hCTPS2, F: CCGGGAAGCGTGGAGTTCA, R: TGCTGCTGGC AATGATCCCT; hDTYMK, F: GCTGGGAACAAGTG CCGTT, R: ACCAGGTCGGGTTTGGGAAG; hNT5C3, F: CTCTGGGATCCCGCGCTT, R: CTCATGCGCGTCC AAGCAG; hRRM1, F: TTGGATTGTTGCGCCTCTGC, R: CAAGACTGGACTGCGGCTCT; hRRM2, F: GATG AGCCGCTGCTGAGAGA, R: TCTCTCCTCGGGTT TCAGGGA; hTK1, F: TCTCGGGCCGATGTTCTCAG, R: GGTGTTCCGGTCATGTGTGC; hTYMS, F: ACC CTGTCGGTATTCGGCAT, R: AAGTCTCGGGATCC ATTGGCA; hUCK2, F: CGGCAAGTCTTCCGTGTGTG, R: AAGGCATCCGGGTGGTCAAA; hUCKL1, F: ACCA GTCGCGACGAGTTCAT, R: ACACCGGTGATCTG CTTCCC ; GAPDH, F: TGTTCGACAGTCAGCCGC, R: GGTGTCTGAGCGATGTGGC;

\section{Western blotting}

Total cellular proteins were extracted by RIPA lysis buffer and then quantified by Bradford method (Sigma). The protein lysates were separated on SDS-PAGE, electroblotted onto PVDF membranes (Millipore), probed with primary antibody followed by HRP-conjugated secondary antibody, and then detected by enhanced chemiluminescence (ECL).

\section{In silico detection of expression of metabolic genes in cancers}

The expression status of metabolic enzymes in liver cancer (LIHC) patients of TCGA was obtained from The Cancer Genome Atlas project (TCGA, https://tcgadata.nci.nih.gov/tcga/). The transcriptome datasets of HCC performed in microarray were downloaded from GEO database. Gene expression was quantified using RSEM (RNA-Seq by Expectation-Maximization) [45] and probe intensity for RNA-seq and microarray datasets, respectively. Quantified RNA expression in TCGA is using RSEM a generative model to estimate RNA expression by EM algorithm and available for download. RLE score 
was calculated based on the sum of expression value of 22 upregulated RLEs or the sum of expression value of 77 downregulated RLEs in TCGA. The two populations of HCC patients with high and low RLE scores were further classified and performed the gene set enrichment analysis (GSEA) and survival analysis by Cutoff finder [46].

\section{Spheroid formation assays}

Briefly, 1,000 cells were suspended in DMEM/F12 medium containing $20 \mathrm{ng} / \mathrm{ml} \mathrm{EGF,} 20 \mathrm{ng} / \mathrm{ml}$ basic FGF and B27 supplements. Cells with limiting dilutions were cultured in 12-well plates for 2 weeks. Spheroids larger than $100 \mu \mathrm{m}$ were then counted for spheroid-forming index.

\section{Chemo-resistance assays}

$10^{4}$ cells were cultured in the absence or presence of $50 \mu \mathrm{M}$ Cisplatin (Sigma) for two days. The cell viability was further analyzed by PrestoBlue ${ }^{\circledR}$ Cell Viability Reagent (Invitrogen).

\section{Whole-cell dTTP extraction and quantification}

$10^{6}$ cells were extracted with $60 \%$ ice-cold methanol, immersed at $100^{\circ} \mathrm{C}$ dry bath for $3 \mathrm{~min}$ and then dried under vacuum according to the method described [47]. The dry residual was further dissolved in $80 \mu \mathrm{l}$ of nuclease-free water and then detected dTTP levels by following Ferraro et al procedure [48].

\section{Immunohistochemistry}

HCC tissue arrays were deparaffinized and subjected to $10 \mathrm{mM}$ citrate buffer ( $\mathrm{pH6}$.0) by microwave treatment for 20 minutes for antigen retrieval. The samples were subsequently immersed in $3 \% \mathrm{H}_{2} \mathrm{O}_{2}$ for $30 \mathrm{~min}$ to block endogenous peroxidase, and then incubated with primary antibodies of TK1, TYMS and DTYMK diluted in blocking buffer at $4{ }^{\circ} \mathrm{C}$ overnight. The slides were processed using EnVision+Dual Link System-HRP kit (DAKO) according to the manufacturer's protocol, and counterstained using hematoxylin. Tissue arrays were purchased from SUPER BIO CHIPS (www.tissue-array.com, Seoul, Korea). All IHC results were examined and scored from 1 to 4 based on their expression intensity by two independent pathologists and defined the intensity score above 3 as high level protein expression.

\section{Flow cytometry analysis for ALDH1 stem cell population}

For Aldefluor assay, $5 \times 10^{5}$ cells were suspended in ALDEFLUOR assay buffer containing ALDH1 substrate according to manufacturer's instructions (Stem Cell Technologies, Durham, NC, USA).

\section{Gene set enrichment analysis (GSEA)}

GSEA was performed on various gene signatures by comparing gene sets from MSigDB database or from published gene signatures [49]. Gene sets with a false discovery rate (FDR) value $<0.05$ by comparing the enrichment score to enrichment results generated from 1,000 random permutations were considered as statistical significance.

\section{Statistical and survival analysis}

Data was expressed as the mean $\pm \mathrm{SD}$. All statistical analyses were conducted using Student's t-test by the SPSS statistical software program (v17.0; SPSS Inc.). Statistical significance was set at $* \mathrm{P} \leq 0.05, * * \mathrm{P} \leq 0.001$ $* * * \mathrm{p}<0.0001$ by two-tailed Student's t-test. The chi square test was applied to evaluate the correlation between RLE score and CD44 expression. The high and low populations in RLE score and CD44 expression was selected by first and fourth quantiles respectively. The survival analysis was assessed with cutoff finder at the website http:// molpath.charite.de/cutoff/index.jsp [46].

\section{Antibodies, cell lines and plasmids}

Antibodies used in our experiments are TK1, TYMS and DTYMK (Genetex); $\beta$-actin (Santa Cruz Biotechnology). Human HCC cell lines PLC5, HepG2, Hep3B, SNU387, SNU449 and SK-Hep1 were maintained in low passage culture as previous described [50]. The full-length TK1, TYMS and DTYMK cDNAs were cloned into pCDNA3.1+ plasmid and deposited into addgene as 100544,100545 and 100546 , respectively

\section{Small hairpin RNA and lentiviral infections to cells}

The small hairpin RNAs (shRNAs) for TK1, TYMS and DTYMK were obtained from the TRC library: TRCN0000010135 and TRCN0000318729 as shTK1; TRCN0000291719 and TRCN0000291720 as shTYMS; TRCN0000199082 and TRCN0000199534 as shDTYMK; from the National RNAi Core Facility Platform of Academia Sinica. Lentiviral preparation and virus infection were performed as previous described [50]. In brief, pLKO.1 with shRNA, pMD.G and pCMV- $\triangle \mathrm{R} 8.91$ were introduced into HEK293T cells for lentiviral packaging. The viral supernatants were collected and used to infect HCC cancer cell lines. Control vector expressing shRNA against LacZ (pLKO.1-shLacZ) was used as a negative control.

\section{Author contributions}

H.W.Y., S.S.L., and Y.S.J. designed and performed the research; S.S.L. performed bioinformatics analysis; H.W.Y. and Y.S.J. analyzed the data and wrote the paper. C.Y. C. performed IHC experiments. C.M.H. helps us 
on dTTP-related experiments. The authors declare no competing financial interests.

\section{ACKNOWLEDGMENTS}

Our work has been supported by grants from Academia Sinica and MOST [106-0210-01-1502] and by the MOST, Taiwan with grant numbers MOST1012325B001011, MOST1012320B001029MY3 and MOST1042320B001009MY3. We thank the TLCN (Taiwan Liver Cancer Network) for providing the HCC tissue samples and related clinical data. We thank Common Equipment Core of IBMS and Academia Sinica including microscopy, DNA sequencing and Flow Cytometry for supporting our experiments.

\section{CONFLICTS OF INTEREST}

The authors declare no conflicts of interest.

\section{REFERENCES}

1. Global Burden of Disease Cancer Collaboration, Fitzmaurice C, Allen C, Barber RM, Barregard L, Bhutta ZA, Brenner H, Dicker DJ, Chimed-Orchir O, Dandona R, Dandona L, Fleming T, Forouzanfar MH, et al. Global, regional, and national cancer incidence, mortality, years of life lost, years lived with disability, and disabilityadjusted life-years for 32 cancer groups, 1990 to 2015: a systematic analysis for the global burden of disease study. JAMA Oncol. 2017; 3: 524-48. https://doi.org/10.1001/ jamaoncol.2016.5688.

2. Waller LP, Deshpande V, Pyrsopoulos N. Hepatocellular carcinoma: a comprehensive review. World J Hepatol. 2015; 7: 2648-63. https://doi.org/10.4254/wjh.v7.i26.2648.

3. Byam J, Renz J, Millis JM. Liver transplantation for hepatocellular carcinoma. Hepatobiliary Surg Nutr. 2013; 2: 22-30. https://doi.org/10.3978/j.issn.2304-3881.2012.11.03.

4. Tung-Ping Poon R, Fan ST, Wong J. Risk factors, prevention, and management of postoperative recurrence after resection of hepatocellular carcinoma. Ann Surg. 2000; 232: 10-24.

5. Zhou XD. Recurrence and metastasis of hepatocellular carcinoma: progress and prospects. Hepatobiliary Pancreat Dis Int. 2002; 1: 35-41.

6. Cheng AL, Kang YK, Chen Z, Tsao CJ, Qin S, Kim JS, Luo R, Feng J, Ye S, Yang TS, Xu J, Sun Y, Liang H, et al. Efficacy and safety of sorafenib in patients in the AsiaPacific region with advanced hepatocellular carcinoma: a phase III randomised, double-blind, placebo-controlled trial. Lancet Oncol. 2009; 10: 25-34. https://doi.org/10.1016/ s1470-2045(08)70285-7.

7. Llovet JM, Ricci S, Mazzaferro V, Hilgard P, Gane E, Blanc JF, de Oliveira AC, Santoro A, Raoul JL, Forner A, Schwartz M, Porta C, Zeuzem S, et al. Sorafenib in advanced hepatocellular carcinoma. N Engl J Med. 2008; 359: 378-90. https://doi.org/10.1056/NEJMoa0708857.

8. Hanahan D, Weinberg RA. Hallmarks of cancer: the next generation. Cell. 2011; 144: 646-74. https://doi. org/10.1016/j.cell.2011.02.013.

9. Warburg $\mathrm{OH}$. The Metabolism of Tumours: Investigations from the Kaiser Wilhelm Institute for Biology, BerlinDahlem. London, UK: Arnold Constable. 1930.

10. Zhang J, Pavlova NN, Thompson CB. Cancer cell metabolism: the essential role of the nonessential amino acid, glutamine. EMBO J. 2017. https://doi.org/10.15252/ embj.201696151.

11. Vander Heiden MG, DeBerardinis RJ. Understanding the Intersections between metabolism and cancer biology. Cell. 2017; 168: 657-69. http://dx.doi.org/10.1016/j.cell.2016.12.039.

12. Gottlieb E, Tomlinson IP. Mitochondrial tumour suppressors: a genetic and biochemical update. Nat Rev Cancer. 2005; 5: 857-66. https://doi.org/10.1038/nrc1737.

13. Possemato R, Marks KM, Shaul YD, Pacold ME, Kim D, Birsoy K, Sethumadhavan S, Woo HK, Jang HG, Jha AK, Chen WW, Barrett FG, Stransky N, et al. Functional genomics reveal that the serine synthesis pathway is essential in breast cancer. Nature. 2011; 476: 346-50. https://doi.org/10.1038/nature10350.

14. Locasale JW, Grassian AR, Melman T, Lyssiotis CA, Mattaini KR, Bass AJ, Heffron G, Metallo CM, Muranen T, Sharfi H, Sasaki AT, Anastasiou D, Mullarky E, et al. Phosphoglycerate dehydrogenase diverts glycolytic flux and contributes to oncogenesis. Nat Genet. 2011; 43: 869-74. https://doi.org/10.1038/ng.890.

15. Schulze A, Harris AL. How cancer metabolism is tuned for proliferation and vulnerable to disruption. Nature. 2012; 491: 364-73. https://doi.org/10.1038/nature11706.

16. Dang L, White DW, Gross S, Bennett BD, Bittinger MA, Driggers EM, Fantin VR, Jang HG, Jin S, Keenan MC, Marks KM, Prins RM, Ward PS, et al. Cancer-associated IDH1 mutations produce 2-hydroxyglutarate. Nature. 2009; 462: 739-44. https://doi.org/10.1038/nature08617.

17. Loo JM, Scherl A, Nguyen A, Man FY, Weinberg E, Zeng Z, Saltz L, Paty PB, Tavazoie SF. Extracellular metabolic energetics can promote cancer progression. Cell. 2015; 160: 393-406. https://doi.org/10.1016/j.cell.2014.12.018.

18. Nomura DK, Long JZ, Niessen S, Hoover HS, Ng SW, Cravatt BF. Monoacylglycerol lipase regulates a fatty acid network that promotes cancer pathogenesis. Cell. 2010; 140: 49-61. https://doi.org/10.1016/j.cell.2009.11.027.

19. Gaude E, Frezza C. Tissue-specific and convergent metabolic transformation of cancer correlates with metastatic potential and patient survival. Nat Commun. 2016; 7: 13041. https://doi.org/10.1038/ncomms13041.

20. Piskounova E, Agathocleous M, Murphy MM, Hu Z, Huddlestun SE, Zhao Z, Leitch AM, Johnson TM, DeBerardinis RJ, Morrison SJ. Oxidative stress inhibits distant metastasis by human melanoma cells. Nature. 2015; 527: 186-91. https://doi.org/10.1038/nature15726. 
21. Massague J, Obenauf AC. Metastatic colonization by circulating tumour cells. Nature. 2016; 529: 298-306. https://doi.org/10.1038/nature17038.

22. Scheel C, Weinberg RA. Cancer stem cells and epithelialmesenchymal transition: concepts and molecular links. Semin Cancer Biol. 2012; 22: 396-403. https://doi. org/10.1016/j.semcancer.2012.04.001.

23. Shaul YD, Freinkman E, Comb WC, Cantor JR, Tam WL, Thiru P, Kim D, Kanarek N, Pacold ME, Chen WW, Bierie B, Possemato R, Reinhardt F, et al. Dihydropyrimidine accumulation is required for the epithelial-mesenchymal transition. Cell. 2014; 158: 1094-109. https://doi.org/10.1016/j. cell.2014.07.032.

24. Neumann O, Kesselmeier M, Geffers R, Pellegrino R, Radlwimmer B, Hoffmann K, Ehemann V, Schemmer $\mathrm{P}$, Schirmacher P, Lorenzo Bermejo J, Longerich $\mathrm{T}$. Methylome analysis and integrative profiling of human HCCs identify novel protumorigenic factors. Hepatology. 2012; 56: 1817-27. https://doi.org/10.1002/hep.25870.

25. Wang YP, Yu GR, Lee MJ, Lee SY, Chu IS, Leem SH, Kim DG. Lipocalin-2 negatively modulates the epithelialto-mesenchymal transition in hepatocellular carcinoma through the epidermal growth factor (TGF-beta1)/Lcn2/ Twist1 pathway. Hepatology. 2013; 58: 1349-61. https:// doi.org/10.1002/hep.26467.

26. Zhao M, Chen X, Gao G, Tao L, Wei L. RLEdb: a database of rate-limiting enzymes and their regulation in human, rat, mouse, yeast and E. coli. Cell Res. 2009; 19: 793-5.

27. Wong CC, Gaspar-Maia A, Ramalho-Santos M, Reijo Pera RA. High-efficiency stem cell fusion-mediated assay reveals Sall4 as an enhancer of reprogramming. PLoS One. 2008; 3: e1955. https://doi.org/10.1371/journal.pone.0001955.

28. Ben-Porath I, Thomson MW, Carey VJ, Ge R, Bell GW, Regev A, Weinberg RA. An embryonic stem cell-like gene expression signature in poorly differentiated aggressive human tumors. Nat Genet. 2008; 40: 499-507. https://doi. org/http://www.nature.com/ng/journal/v40/n5/suppinfo/ ng.127_S1.html.

29. Liberzon A, Birger C, Thorvaldsdóttir H, Ghandi M, Mesirov Jill P, Tamayo P. The molecular signatures database hallmark gene set collection. Cell Syst. 2015; 1: 417-25. https://doi.org/https://doi.org/10.1016/j.cels.2015.12.004.

30. Feng D, Wang N, Hu J, Li W. Surface markers of hepatocellular cancer stem cells and their clinical potential. Neoplasma. 2014; 61: 505-13. https://doi.org/10.4149/neo_2014_061.

31. Yang ZF, Ho DW, Ng MN, Lau CK, Yu WC, Ngai P, Chu PW, Lam CT, Poon RT, Fan ST. Significance of CD90+ cancer stem cells in human liver cancer. Cancer Cell. 2008; 13: 153-66. https://doi.org/10.1016/j.ccr.2008.01.013.

32. Chang IC, Huang SF, Chen PJ, Chen CL, Chen CL, $\mathrm{Wu} \mathrm{CC}$, Tsai CC, Lee $\mathrm{PH}$, Chen MF, Lee CM, Yu HC, Lo GH, Yeh CT, et al. The hepatitis viral status in patients with hepatocellular carcinoma: a study of 3843 patients from Taiwan Liver Cancer Network. Medicine
(Baltimore). 2016; 95: e3284. https://doi.org/10.1097/ md.031470R1031470R13284.

33. Yang Y, Li C, Nie X, Feng X, Chen W, Yue Y, Tang H, Deng F. Metabonomic studies of human hepatocellular carcinoma using high-resolution magic-angle spinning $1 \mathrm{H}$ NMR spectroscopy in conjunction with multivariate data analysis. J Proteome Res. 2007; 6: 2605-14. https://doi. org/10.1021/pr070063h.

34. Calvisi DF, Wang C, Ho C, Ladu S, Lee SA, Mattu $\mathrm{S}$, Destefanis G, Delogu S, Zimmermann A, Ericsson J, Brozzetti S, Staniscia T, Chen X, et al. Increased lipogenesis, induced by AKT-mTORC1-RPS6 signaling, promotes development of human hepatocellular carcinoma. Gastroenterology. 2011; 140: 1071-83. https://doi. org/10.1053/j.gastro.2010.12.006.

35. Yamashita T, Honda M, Takatori H, Nishino R, Minato H, Takamura H, Ohta T, Kaneko S. Activation of lipogenic pathway correlates with cell proliferation and poor prognosis in hepatocellular carcinoma. J Hepatol. 2009; 50: 100-10. https://doi.org/10.1016/j.jhep.2008.07.036.

36. Yahagi N, Shimano H, Hasegawa K, Ohashi K, Matsuzaka T, Najima Y, Sekiya M, Tomita S, Okazaki H, Tamura Y, Iizuka Y, Ohashi K, Nagai R, et al. Co-ordinate activation of lipogenic enzymes in hepatocellular carcinoma. Eur J Cancer. 2005; 41: 1316-22. https://doi.org/10.1016/j. ejca.2004.12.037.

37. Nelson ME, Lahiri S, Chow JD, Byrne FL, Hargett SR, Breen DS, Olzomer EM, Wu LE, Cooney GJ, Turner N, James DE, Slack-Davis JK, Lackner C, et al. Inhibition of hepatic lipogenesis enhances liver tumorigenesis by increasing antioxidant defence and promoting cell survival. Nat Commun. 2017; 8: 14689. https://doi.org/10.1038/ ncomms14689.

38. Li J, Condello S, Thomes-Pepin J, Ma X, Xia Y, Hurley TD, Matei D, Cheng JX. Lipid desaturation is a metabolic marker and therapeutic target of ovarian cancer stem cells. Cell Stem Cell. 2017; 20: 303-14. e5. https://doi. org/10.1016/j.stem.2016.11.004.

39. Burdelski C, Strauss C, Tsourlakis MC, Kluth M, HubeMagg C, Melling N, Lebok P, Minner S, Koop C, Graefen M, Heinzer H, Wittmer C, Krech T, et al. Overexpression of thymidylate synthase (TYMS) is associated with aggressive tumor features and early PSA recurrence in prostate cancer. Oncotarget. 2015; 6: 8377-87. https://doi.org/10.18632/ oncotarget. 3107.

40. Wang X, Sun X, Du X, Zhou F, Yang F, Xing J, Dong G, Guo X. Thymidylate synthase gene polymorphisms as important contributors affecting hepatocellular carcinoma prognosis. Clin Res Hepatol Gastroenterol. 2016. https:// doi.org/10.1016/j.clinre.2016.10.012.

41. Longley DB, Harkin DP, Johnston PG. 5-fluorouracil: mechanisms of action and clinical strategies. Nat Rev Cancer. 2003; 3: 330-8. https://doi.org/10.1038/nrc1074.

42. Liu Y, Marks K, Cowley GS, Carretero J, Liu Q, Nieland TJ, Xu C, Cohoon TJ, Gao P, Zhang Y, Chen Z, Altabef 
$\mathrm{AB}$, Tchaicha JH, et al. Metabolic and functional genomic studies identify deoxythymidylate kinase as a target in LKB1-mutant lung cancer. Cancer Discov. 2013; 3: 870-9. https://doi.org/10.1158/2159-8290.CD-13-0015.

43. de Angelis PM, Fjell B, Kravik KL, Haug T, Tunheim SH, Reichelt W, Beigi M, Clausen OP, Galteland E, Stokke T. Molecular characterizations of derivatives of HCT116 colorectal cancer cells that are resistant to the chemotherapeutic agent 5-fluorouracil. Int J Oncol. 2004; 24: 1279-88.

44. Deshmukh A, Deshpande K, Arfuso F, Newsholme P, Dharmarajan A. Cancer stem cell metabolism: a potential target for cancer therapy. Mol Cancer. 2016; 15: 69. https:// doi.org/10.1186/s12943-016-0555-x.

45. Li B, Dewey CN. RSEM: accurate transcript quantification from RNA-Seq data with or without a reference genome. BMC Bioinformatics. 2011; 12: 323. https://doi. org/10.1186/1471-2105-12-323.

46. Budczies J, Klauschen F, Sinn BV, Gyorffy B, Schmitt WD, Darb-Esfahani S, Denkert C. Cutoff Finder: a comprehensive and straightforward Web application enabling rapid biomarker cutoff optimization. PLoS One. 2012; 7: e51862. https://doi.org/10.1371/journal.pone.0051862.

47. Hu CM, Yeh MT, Tsao N, Chen CW, Gao QZ, Chang CY, Lee MH, Fang JM, Sheu SY, Lin CJ, Tseng MC, Chen YJ, Chang ZF. Tumor cells require thymidylate kinase to prevent dUTP incorporation during DNA repair. Cancer Cell. 2012; 22: 36-50. https://doi.org/10.1016/j.ccr.2012.04.038.

48. Ferraro P, Franzolin E, Pontarin G, Reichard P, Bianchi V. Quantitation of cellular deoxynucleoside triphosphates. Nucleic Acids Res. 2010; 38: e85. https://doi.org/10.1093/nar/gkp1141.

49. Subramanian A, Tamayo P, Mootha VK, Mukherjee S, Ebert BL, Gillette MA, Paulovich A, Pomeroy SL, Golub TR, Lander ES, Mesirov JP. Gene set enrichment analysis: a knowledge-based approach for interpreting genome-wide expression profiles. Proc Natl Acad Sci U S A. 2005; 102 : 15545-50. https://doi.org/10.1073/pnas.0506580102.

50. Chang CY, Lin SC, Su WH, Ho CM, Jou YS. Somatic LMCD1 mutations promoted cell migration and tumor metastasis in hepatocellular carcinoma. Oncogene. 2012; 31: 2640-52. https://doi.org/10.1038/onc.2011.440. 